\title{
Novel Applications of Super-Resolution Microscopy in Molecular Biology and Medical Diagnostics
}

\author{
Dissertation
}

\author{
in partial fulfillment of the requirements for the degree \\ "Doctor of Natural Sciences (Doctor rerum naturalium)" \\ of the Georg August University Göttingen
}

within the doctoral program Molecular Physiology of the Brain

submitted by

WILLIAM I. ZHANG

born in

GÖTTINGEN, GERMANY

Göttingen, September 2015 


\title{
Novel Applications of Super-Resolution Microscopy in Molecular Biology and Medical Diagnostics
}

\section{Dissertation}

\author{
in partial fulfillment of the requirements for the degree \\ "Doctor of Natural Sciences (Doctor rerum naturalium)" \\ of the Georg August University Göttingen
}

within the doctoral program Molecular Physiology of the Brain

submitted by

WILLIAM I. ZHANG

born in

GÖTTINGEN, GERMANY

Göttingen, September 2015 


\section{THESIS COMMITTEE}

Prof. Dr. Silvio O. Rizzoli; Dept. of Neuro- \& Sensory Physiology, University Medical Center, Göttingen, Germany

Prof. Dr. Tiago Outeiro; Dept. of Neurodegeneration and Restorative Research, University Medical Center, Göttingen, Germany

Prof. Dr. Gerhard Braus; Institute for Microbiology and Genetics, University of Göttingen, Göttingen, Germany

\section{MEMBERS OF THE EXAMINATION BOARD}

1st referee

Prof. Dr. med. Anja Schneider, Translational Dementia Research, German Center for Neurodegenerative Diseases (DZNE) within the Helmholtz Association, Dept. of Psychiatry and Psychotherapy, University Medical Center, Göttingen, Germany

2nd referee

Prof. Dr. Stefan Jakobs; Dept. of NanoBiophotonics, Mitochondrial Structure and Dynamics, MaxPlanck-Institute for Biophysical Chemistry, Göttingen, Germany

3rd referee

Prof. Dr. Paul Lingor; Dept. of Neurology, University Medical Center, Göttingen, Germany

Date of thesis defense:

18th November 2015 
I hereby declare that I prepared this dissertation independently and with no other sources and aids than quoted.

Göttingen, 30th September 2015 


\title{
S tudy
}

\section{C reativity}

\section{I nnovation}

\author{
E nthusiasm
}

N etwork

C ourage

E ndurance 
Table of contents

Table of contents

List of Publications

Acknowledgements

List of media

List of abbreviations

\section{Fehler! Textmarke nicht definiert.}

9

10

11

12

14

15

1.1. A brief history of microscopy and imaging 15

(I) Equation | Abbe's equation of diffraction limit................................................................16

1.2. A recent milestone in fluorescent microscopy: nanoscopy 17

(1) Figure | Schematic overview of the functionality of STED..........................................17

(II) Equation | Lateral resolution of STED microscopy......................................................18

1.3. Nanoscopy in molecular biology: RNA research 18

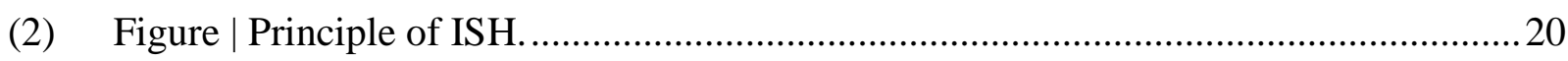

1.4. Nanoscopy in medicine: AD research 20

(3) Figure | Proteolytic processing of APP and formation of plaques...................................21

1.4.1. Current state of AD diagnosis 22

1.5. Scope of this work 23

2. Results 25

2.1. Establishing a FISH protocol for STED microscopy 25

2.1.1. STED-FISH stains mRNAs specifically 25

(4) Figure | Cos-7 cells transiently transfected with fusion versions of synaptic proteins....26

(5) Figure | Comparison of spot densities between probes targeting the UTRs and CDSs...27

2.1.2. Three probes per RNA target are sufficient for reliable detection $\quad 27$

(6) Figure | Histogram of spot intensities with regard to number of probes used..................27

2.1.3. STED-FISH provides information about RNA organization 28

(7) Figure | STED provides more accurate information than confocal microscopy...............28

(8) Figure | STED-FISH is able to resolve mRNA organization.........................................29

2.1.4. STED-FISH is able to monitor mRNA levels qualitatively 29

(9) Figure | Changes in mRNA levels with respect to age in vitro.........................................30

2.2. Establishing a microscopy-based diagnosis method for AD 30

(10) Figure | Schematic overview of the experimental procedure. …………………….............31

2.2.1. Optimization of coverslip coating and fixation 31

(11) Figure | Epifluorescence images of coating and fixation optimization. ............................32 
(12) Figure | Epifluorescence images of the optimization of blocking conditions. 34

2.2.3. Super-resolution is able to separate assemblies of different sizes

(13) Figure / Comparison of immunostained CSF imaged by confocal and STED microscopy. 35

(14) Figure | STED assessment of low (LMW) and high molecular weight (HMW) A $\beta$ assemblies produced in vitro.

2.2.4. AD patients show fewer, smaller, and dimmer spots than controls

(15) Figure $\mid$ Analysis of CSF A $\beta$ by STED imaging. 37

2.2.5. STED parameters of tau increased prediction accuracy

(16) Figure | Analysis of CSF tau by STED imaging and prediction accuracy of STED.......38

(III) Equation $\mid$ Discriminator function using STED parameters from $A \beta$ data.

(IV) Equation | Discriminator function using STED parameters from $A \beta$ and tau data. 39

(17) Figure / Comparison of STED and ELISA prediction accuracies. .39

2.2.6. STED parameters of two $\mathrm{MCl}$ patients were within $\mathrm{AD}$ range 40

(18) Figure | STED values of MCI patients with respect to the averages of AD patients (grey) and controls (black).

3. Discussion

3.1. Technical limitations

3.2. Technical limitations of FISH

3.2.1. Loss of RNA

3.2.2. Inefficient blocking

3.2.3. Signal amplification

3.3. Technical limitations - AD

3.3.1. Limitations of the field

3.4. Outlook

4. Material and methods $\quad 46$

4.1. General chemicals and manufacturers 46

(A) Table / List of manufacturers and institutes. .46

4.2. Buffers and solutions

4.3. Antibodies

(B) Table / List of antibodies. 48

4.4. Coverslip preparation

4.5. Cell culture

4.6.1. PC12 cells

4.6.2. COS-7 cells

4.6.3. Neuronal culture 
(C) Table / List of FISH probes with their sequences and fluorophores.

4.6.2. Immunostaining of cells (after FISH) 52

4.7. Immunostaining of CSF 52

4.7.1. Synthetic $A \beta$ samples 52

4.7.2. Human subjects 53

4.7.3. CSF samples 53

(D) Table | Patient information and CSF properties from controls......................................54

(E) Table $\mid$ Patient information and CSF properties from AD patients.................................54

(F) Table $\mid$ Patient information and CSF properties from AD cases confirmed by autopsy..55

(G) Table / Patient information and CSF properties from mild cognitive impaired (MCI)...56

4.7.4. Immunostaining 56

4.8. Epifluorescence imaging 56

(H) Table | List of filter cubes for epifluorescence imaging. ...............................................5

4.9. Confocal and STED imaging 57

4.10. Image analysis 57

4.11. Statistics 57

5. Bibliography 59 


\section{List of Publications}

Lewis MA, Buniello A, Hilton JM, Zhu F, Zhang WI, Evans S, van Dongen S, Enright A, Steel KP (2016) Exploring regulatory networks of miR-96 in the developing inner ear. Sci Rep, accepted.

Zhang WI, Antonios G, Rabano A, Bayer TA, Schneider A, Rizzoli SO (2015) Super-resolution microscopy of CSF biomarkers as a tool for Alzheimer's disease diagnostics. J Alzheimer Dis, epub 2015 Apr 15.

Zhang WI, Röhse H, Rizzoli SO, Opazo F (2014) Fluorescent in situ hybridization of synaptic proteins imaged with super-resolution STED microscopy. Microsc Res Tech 77, 517-527. 


\section{Acknowledgements}

First and foremost, I would like to thank Silvio Rizzoli from the bottom of my heart. He was not only my PI who guided me scientifically, I can honestly say that he has been my mentor. Without his support, I would not be where I am now.

I also would like to thank my thesis committee members Anja Schneider, Tiago Outeiro, and Gerhard Braus for their support during the $\mathrm{PhD}$ project, providing scientific input and encouragement throughout the doctorate; and Stefan Jakobs and Paul Lingor, for being part of the extended committee.

Personal thanks go to everyone who supported me during this very dynamic phase of my life. You know who you are and I sincerely thank you more than words can say. 


\section{List of media}

\begin{tabular}{|c|c|c|}
\hline object & title & page \\
\hline Equation I & Abbe's equation of diffraction limit. & 20 \\
\hline Figure 1 & Schematic overview of the functionality of STED. & 22 \\
\hline Equation II & Lateral resolution of STED microscopy. & 22 \\
\hline \multirow{2}{*}{$\begin{array}{l}\text { Figure } 2 \\
\text { Figure } 3\end{array}$} & Principle of ISH. & 24 \\
\hline & Proteolytic processing of APP and formation of plaques. & 26 \\
\hline \multirow{2}{*}{$\begin{array}{l}\text { Figure } 4 \\
\text { Figure } 5\end{array}$} & Cos-7 cells transiently transfected with fusion versions of synaptic proteins. & 30 \\
\hline & Comparison of spot densities between probes targeting the UTRs and CDSs. & 31 \\
\hline \multirow{2}{*}{$\begin{array}{l}\text { Figure } 6 \\
\text { Figure } 7\end{array}$} & Histogram of spot intensities with regard to the number of probes used. & 32 \\
\hline & STED provides more accurate information than confocal microscopy. & 33 \\
\hline Figure 8 & STED-FISH is able to resolve mRNA organization. & 34 \\
\hline Figure 9 & Changes in mRNA levels with respect to age in vitro. & 35 \\
\hline Figure 10 & Schematic overview of the experimental procedure. & 35 \\
\hline Figure 11 & Epifluorescence images of coating and fixation optimization. & 37 \\
\hline Figure 12 & Epifluorescence images of the optimization of blocking conditions. & 39 \\
\hline Figure 13 & Comparison of immunostained CSF imaged by confocal and STED microscopy. & 40 \\
\hline Figure 14 & $\begin{array}{l}\text { STED assessment of low (LMW) and high molecular weight (HMW) A } \mathrm{A} \text { assemblies } \\
\text { produced in vitro. }\end{array}$ & 41 \\
\hline Figure 15 & Analysis of CSF A $\beta$ by STED imaging. & 42 \\
\hline \multirow{2}{*}{$\begin{array}{l}\text { Figure } 16 \\
\text { Equation III }\end{array}$} & Analysis of CSF tau by STED imaging and prediction accuracy of STED. & 43 \\
\hline & Discriminator function using the STED parameters from $A \beta$ data. & 44 \\
\hline \multirow{2}{*}{$\begin{array}{l}\text { Equation IV } \\
\text { Figure } 17\end{array}$} & Discriminator function using the STED parameters from $A \beta$ and tau data. & 44 \\
\hline & Comparison of STED and ELISA prediction accuracies. & 44 \\
\hline \multirow{2}{*}{$\begin{array}{l}\text { Figure } 18 \\
\text { Table A }\end{array}$} & $\begin{array}{l}\text { STED values of } \mathrm{MCl} \text { patients with respect to averages of } \mathrm{AD} \text { patients (grey) and } \\
\text { controls (black). }\end{array}$ & 45 \\
\hline & List of manufacturers and institutes. & 51 \\
\hline Table B & List of antibodies. & 53 \\
\hline Table C & List of FISH probes with their sequences and fluorophores. & 55 \\
\hline Table D & Patient information and CSF properties from controls. & 59 \\
\hline Table E & Patient information and CSF properties from AD patients. & 60 \\
\hline Table F & Patient information and CSF properties from AD cases confirmed by autopsy. & 60 \\
\hline Table G & Patient information and CSF properties from mild cognitive impaired $(\mathrm{MCl})$. & 61 \\
\hline Table H & List of filter cubes for epifluorescence imaging. & 62 \\
\hline
\end{tabular}




\section{List of abbreviations}

\begin{tabular}{|c|c|}
\hline$A \beta$ & $\beta$-amyloid \\
\hline$A D$ & Alzheimer's disease \\
\hline APD & avalanche photo diode \\
\hline APP & amyloid precursor protein \\
\hline bp & base pairs \\
\hline CCD & charge-coupled device \\
\hline CDS & coding sequence \\
\hline ciRNA & circular RNA \\
\hline CSF & cerebrospinal fluid \\
\hline DNA & deoxyribonucleic acid \\
\hline (F)ISH & (fluorescence) in situ hybridization \\
\hline HFIP & 1,1,1,3,3,3-hexafluoro-2-propanol \\
\hline HMW & high molecular weight \\
\hline LMW & low molecular weight \\
\hline IncRNA & long non-coding RNA \\
\hline $\mathrm{MCl}$ & mild cognitive impaired \\
\hline miRNA & micro RNA \\
\hline mRNA & messenger RNA \\
\hline $\mathrm{NaCl}$ & sodium chloride \\
\hline $\mathrm{NaOH}$ & sodium hydroxide \\
\hline n.s. & not significant \\
\hline PALM & photo-activated localization microscopy \\
\hline PMT & photo multiplier tube \\
\hline qPCR & quantitative polymerase chain reaction \\
\hline RNA & ribonucleic acid \\
\hline SEC & size-exclusion chromatography \\
\hline STED & stimulated emission depletion \\
\hline STORM & stochastic optical reconstruction microscopy \\
\hline Stg & synaptotagmin \\
\hline Syp & synaptophysin \\
\hline TIRF & total internal reflection fluorescence \\
\hline
\end{tabular}




\begin{tabular}{|l|l|}
\hline Tm & melting temperature \\
\hline tRNA & transfer RNA \\
\hline UTR & untranslated region \\
\hline UV & ultra violet \\
\hline VAMP & synaptobrevin \\
\hline
\end{tabular}




\begin{abstract}
Despite recent advances in microscopy techniques, the underlying labeling assays remained mostly unchanged. However, super-resolution techniques require other staining conditions than conventional light microscopy, like more dense labeling, which is not always trivial to achieve. In this work, I present two novel applications of stimulated emission depletion (STED) microscopy to the fields of molecular biology and medical diagnostics. For one, I established a fluorescent in situ hybridization (FISH) protocol to investigate mRNAs of the three synaptic proteins synaptophysin, synaptobrevin, and synaptotagmin in primary hippocampal neurons. This achieved more precise information regarding the mRNA numbers and organization than conventional confocal microscopy. Secondly, I applied STED microscopy for the development of a novel diagnosis method for Alzheimer's disease (AD). The increased resolution was sufficiently high to discriminate low and high molecular weight $\beta$-amyloid $(\mathrm{A} \beta)$ aggregates produced in vitro. Analysis of cerebrospinal fluid (CSF) samples from $36 \mathrm{AD}$ patients, 11 patients with mild cognitive impairment (MCI), and 21 controls allowed a separation of AD patients from controls with 87\% specificity and $\sim 79 \%$ sensitivity. In conclusion, this work illustrates the need for optimization of long established methods depending on the imaging technique and sample to obtain more accurate data.
\end{abstract}




\section{Introduction}

\subsection{A brief history of microscopy and imaging}

Throughout history, there has always been a fascination about what the world is composed of. However, the human eye can only distinguish two elements if they are at least $0.1 \mathrm{~mm}$ apart, therefore having a spatial resolution of $0.1 \mathrm{~mm}$ (Alberts, 2014). In order to see smaller objects, optical tools have been developed, like magnifying glasses or microscopes. Anton van Leeuwenhoek could be considered as the inventor of the first compound microscope with a sophisticated optical apparatus in the 17th century (Baker, 1739). The first microscopes allowed the investigation of biological samples at unprecedented detail. For example, van Leeuwenhoek discovered spermatozoa and Robert Hooke described the first plant cells (Hooke, 1665, Baker, 1739).

The reason why the sample can be seen under this type of microscopes, bright-field microscopes, is based on varying light scattering and absorption properties of the sample that result in contrast differences. However, most biological samples have only low contrast rendering detailed observations difficult. Staining procedures change the optophysical properties of parts of the sample, thereby increasing the contrast. A famous example would be the silver staining invented by Camillo Golgi in 1873 (Golgi, 1873). This technique introduces silver precipitate into the sample which then appear black in brightfield due to the high light absorption. By highlighting only specific parts, the composition of the sample could be investigated more accurately.

Ramón y Cajal used Golgi’s method that had been around for several years and adapted the staining procedure according to the sample (Ramón y Cajal, 1917). This allowed him to draw his observations in extensive detail. His sketches of Purkinje cells, in particular, are famous. His findings contributed majorly to the knowledge about neuron structure and the cell as elementary component of complex organisms. Ramón y Cajal's findings are a valuable example of how an established method can be improved to obtain new data.

Based on the same principle of restricting the detection to specific parts of the sample, fluorescence microscopy became a milestone in the microscopy field. Instead of white light, which consists of a mixture of light with different wavelengths, fluorescence microscopy uses only parts of the spectrum. This light is absorbed by a fluorescent dye and light with less energy, i.e. at a longer wavelength, is emitted and detected. This results in the maximum contrast by limiting the signal to the location of the staining, while the rest of the sample remains mostly undetected. Another 
advantage of using light from only parts of the spectrum is the improvement of the optical resolution. In 1873, Ernst Abbe published an equation describing the resolution limit of microscopes in relation to the wavelength of light used or light detected, respectively (Equation I; Abbe, 1873). Using only a narrow part of the spectrum therefore reduces the blurriness due to diffraction and increasesb the resolution of the system.

$$
\theta=\frac{A}{2 \sin [\theta]}=\frac{A}{2 \cdot M A}
$$

(I) Equation | Abbe's equation of diffraction limit. This equation describes the theoretical resolution limit of optical systems, where $\lambda$ is the wavelength of light passing through the lens, $\mathrm{n}$ is the refractive index of the medium the light is traveling through, and $\theta$ is the angle the light is entering the lens with.

Fluorescence microscopy requires specific staining methods to introduce the fluorescent dye into the sample. This can be achieved, similar to the silver staining, based on the biophysical properties like hydrophobicity. Another approach would be to label proteins of interest specifically with socalled affinity probes. Affinity probes are molecules that specifically bind to another target molecules non-covalently to enable their detection. The most common technique of the latter approach is immunostaining, which uses fluorescently labeled antibodies.

Confocal microscopes show an even higher resolution based on the same principle to reduce the signal to a very defined and restricted area. A confocal microscope is a fluorescence microscope illuminating only small parts of the sample at a given time. Additionally, it contains a diaphragm, the so-called pinhole, that excludes light from outside the focal plane (z-plane). The improved resolution of confocal microscopes has been used to investigate what cells are comprised of and how the cell functions. Therefore, it is understandable that increased resolution offers a more accurate representation of the cell.

The electron microscope achieves even higher resolutions by substituting light with electrons. The beam of electrons has a shorter wavelength than UV light, within the picometer range (Erni, 2009). However, using electrons requires preparation of the sample under harsh conditions. This procedure is laborious, requires fixation of the sample, and is prone to introduce artifacts (Tapia et al., 2012). Specific labeling of target proteins is rather difficult which makes - despite the inferior resolution fluorescence microscopy more versatile and therefore the method of choice for this work. 


\subsection{A recent milestone in fluorescent microscopy: nanoscopy}

During the past decades, innovations in the field of fluorescence microscopy have managed to circumvent Abbe's diffraction limit. The field of nanoscopy, also named super-resolution microscopy, emerged. The Nobel prize for Chemistry was recently awarded to two of those novel techniques: first, stimulated emission depletion (STED) microscopy by Stefan W. Hell. It reduces the signal to a confined area by application of Albert Einstein's eponymous theory of stimulated depletion (Willig et al., 2006). The principle of stimulated depletion uses photons to stimulate excited electrons of the illuminated fluorophores to fall back to ground state. This results in light emission with the same wavelength as the photons used for de-excitation which can be excluded from detection by filters (Einstein, 1916). This so-called STED effect is applied to the periphery of the diffraction limited fluorescent spot (Figure 1, blue) by superimposing a second, donut-shaped laser beam (red). This allows the detection of only the center of the excited spot, where the power of the STED beam is close to zero (yellow) since the STED laser de-excites fluorophores in relation to its power. The lasers scan, i.e. are moved across the sample, to create the image.

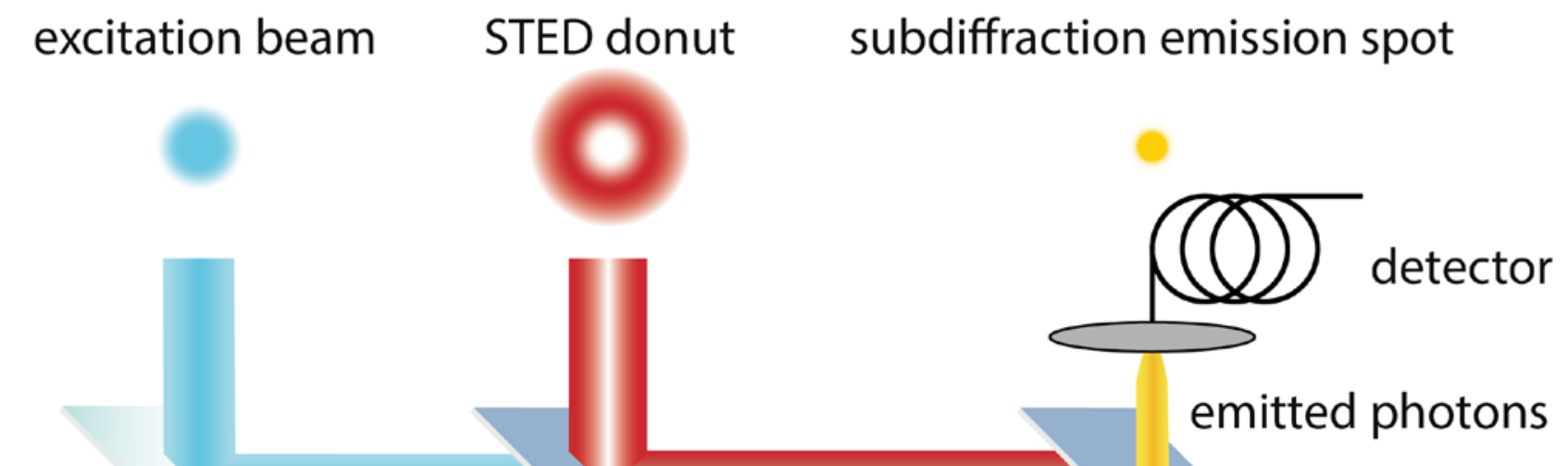

mirror

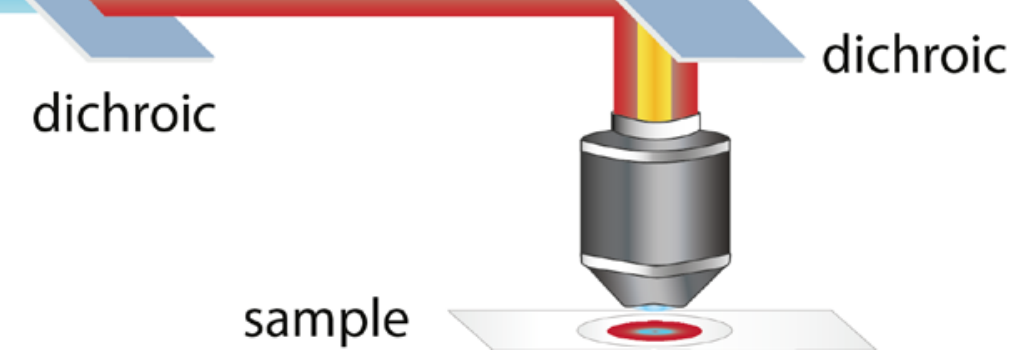

(1) Figure | Schematic overview of the functionality of STED. The sample is excited by a laser (cyan) like in a conventional laser scanning microscope. It is followed by a slightly delayed second laser (red) modulated to the shape of a toroid for de-exciting the previously excited fluorophores. Only the fluorophores in the center of the toroid, where the laser intensity is close to zero, will emit light and thereby creating a subdiffractional spot (yellow). 
Higher intensities correlate with more de-excitation resulting in a smaller focal spot and higher resolution, making STED theoretically not limited to a physical barrier (Equation II). STED microscopy has been used on samples which require high spatial resolution, such as investigation of densely labeled protein clusters in the plasma membrane (Hoopmann et al. 2010; Opazo et al 2010; Sieber et al 2007).

$$
d_{x, y}=\frac{\lambda}{2 n \cdot \sin (\theta) \cdot \sqrt{1+\frac{I}{I_{s a t}}}}
$$

(II) Equation | Lateral resolution of STED microscopy. This equation describes the theoretical resolution limit of optical systems, where $\lambda$ is the wavelength of light, $\mathrm{n}$ is the refractive index of the medium, $\theta$ is the angle the light is entering with, $\mathrm{I}$ is the focal intensity, and $\mathrm{I}_{\text {sat }}$ is the saturation intensity, which describes the value at which the fluorescence is reduced to half. Since $\lambda$, $\mathrm{n}$, and $\theta$ are constants, the lateral resolution is only determined by $\mathrm{I} / \mathrm{I}_{\text {sat }}$ and therefore independent of diffraction.

The second super-resolution principle credited by the 2014 chemistry Nobel prize concerns the detection of the fluorophores in a temporally separated manner rather than in a spatial configuration (Betzig, 2006, Moerner, 2006). Stochastic optical reconstruction microscopy (STORM) exploits the inherent blinking nature of the fluorophores, i.e. fluorescence emission is a stochastic event, while photo-activated localization microscopy (PALM) uses light to switch photo-activatable fluorophores on and off. This allows image acquisition of fluorophore subpopulations at a given time. The diffraction limited spots are likely to be separated further than the diffraction limit and can therefore be located with high precision. A series of images is then used to reconstruct an diffraction unlimited image (reviewed in Toomre and Bewersdorf, 2010). The advantage of PALM/STORM is the simple set up. Both techniques are based on epifluorescence/TIRF microscopes and can be used with a variety of fluorescent dyes. On the other hand, using chip-based detection systems requires a high labeling density due to the inferior sensitivity compared to photon-counting systems, like photo multiplier tubes (PMTs) or avalanche photo diodes (APDs) commonly used for STED microscopy.

\subsection{Nanoscopy in molecular biology: RNA research}

A prominent example of densely labeled structures, where super-resolution is needed, are RNAs. The importance of RNA spikes upon the identification of new RNA species with unidentified function. In the 1950-60s, an intermediate between DNA and protein has been identified, the 
messenger RNA (mRNA) (Jacob, 1961). Around the same time, it was found that ribosomes contain RNA as essential component for translation, which in turn is a process relying on another type of RNA: transfer RNA (tRNA) (Hoagland, 1956). tRNAs are triplets of RNA nucleotides encoding for the different amino acids.

Since the 1990s, several RNA species where identified that do not code for proteins, summarized as non-coding RNAs. One representative are miRNAs, short RNA sequences that regulate protein expression post-transcriptionally (Bartel, 2004). Some miRNAs have been associated with diseases (e.g. Lewis and Steel, 2010), other non-coding RNAs have been discovered recently but their function is still unknown (long non-coding RNAs, lncRNAs; circular RNAs, ciRNAs) (Kapranov et al., 2007, Ebbesen et al., 2015).

Biochemical and PCR-based methods (including sequencing) provide information about their biochemical properties and sequence but are rather limited concerning identification of function. The above mentioned approaches have the disadvantage requiring destruction of the cell. However, the location of the investigated molecule within the intact cell can provide valuable information about its function. Therefore, an imaging based technique for the investigation of RNAs would be desirable. In situ hybridization (ISH) is a method that visualizes nucleic acids (DNA or RNA) by exploiting their intrinsic hybridization properties of the base pairing (guanine:cytosine, adenine:thymine, and adenine:uracil). Labeled DNA or RNA sequences (probes) that are reverse complementary to the target sequence are introduced into the cell. These probes act as affinity probes and hybridize specifically to the target sequence and can then be detected directly or indirectly. The label can be detected directly if it contains a fluorophore (fluorescent in situ hybridization, FISH) or indirectly, which detection requires additional steps like immunostaining (Figure 2), thereby increasing the spot size. Many mRNAs are expressed abundantly in the cytosol, i.e. show a high labeling density. This makes identification of individual RNA molecules difficult, which is exacerbated by diffraction limited imaging techniques. In theory, a FISH protocol using directly labeled probes for super-resolution microscopy should be able to address those issues. 
A

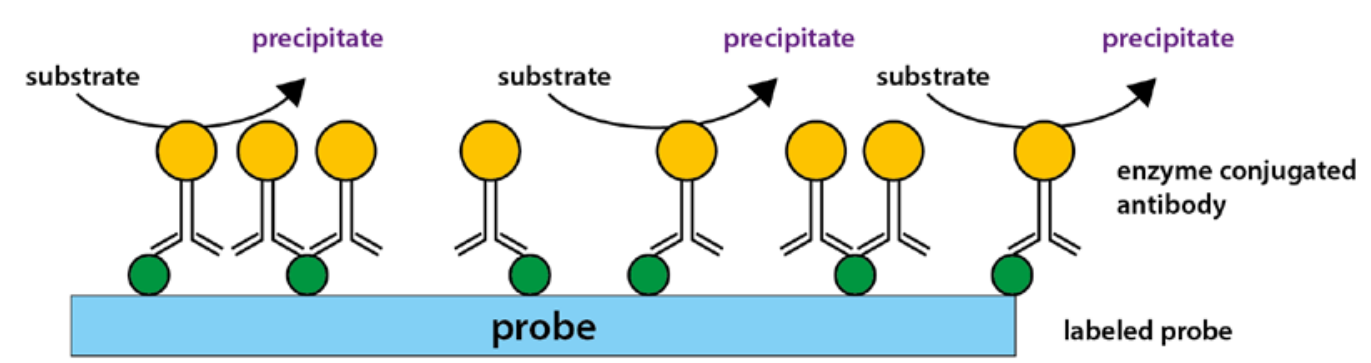

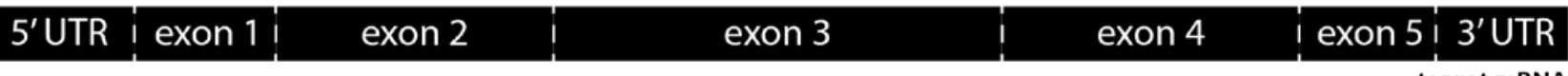

target mRNA

B

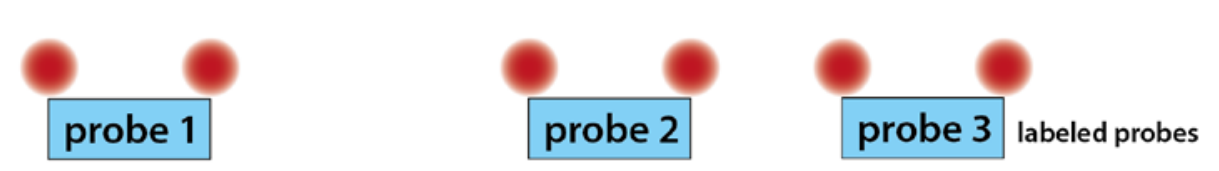

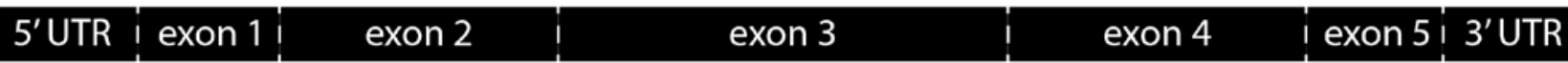

target mRNA

(2) Figure / Principle of ISH. (A) RNA probes (cyan) are produced in vitro with randomly inserted labeled nucleotides, e.g. digoxigenin (DIG, green). The label is detected by enzyme-linked antibodies (yellow) which catalyze a reaction to form a colored precipitate.

(B) Multiple synthetical DNA probes (cyan) with a defined number of fluorophores at a defined location within the probe (red) can be detected by fluorescence microscopy.

\subsection{Nanoscopy in medicine: $A D$ research}

[For text related to the medical part of this work, I may refer to A $\beta$ peptides as proteins for readability, especially in conjunction with tau protein.]

Increased resolution is not only required for investigations of densely labeled samples but also when the size of the target of interest is relevant. One example in the field of medicine would be protein aggregates observed in Alzheimer's disease (AD).

$\mathrm{AD}$ is the most common form of dementia and was first described by Alois Alzheimer in 1907 as a "peculiar disease of the cerebral cortex" (Alzheimer, 1907). The reported female patient showed severe memory deficits and disorientation, while her motor ability remained normal. After her death, the autopsy revealed abnormal intracellular fibrils and macroscopic plaques in the cortex. Alzheimer made those neurofibrillary tangles and amyloid plaques, which became the neuropathological hallmarks of $\mathrm{AD}$, responsible for the degeneration of neurons.

This correlation was established more than 60 years later upon the work of Blessed, Tomlinson, and Roth (Blessed, 1968). The authors investigated post-mortem brain samples with respect to the patients' cognitive capabilities before death. They found that the number plaques correlates with 
dementia severity. Another 15 years later, it was found that those amyloid fibrils and neurofibrillary tangles consist mainly of $\beta$-amyloid $(\mathrm{A} \beta)$ and hyperphosphorylated tau, respectively (Glenner and Wong, 1984, Dickson, 1992, Morris et al., 2011).

The amyloid precursor protein (APP) is a transmembrane protein (Figure 3). It has been related to several functions, including synapse formation and function (Priller et al., 2006), neural plasticity (Turner et al., 2003), and iron metabolism (Duce et al., 2010). Mutations of APP have been associated with abnormally elevated levels of its cleavage product $\mathrm{A} \beta$ causing familial cases of AD (e.g. Scheuner et al., 1996). A $\beta$ is released to the extracellular space upon two successive cleavages of $\beta$ - (orange) and $\gamma$-secretase (green), where it aggregates to oligomers and eventually insoluble fibrils (lower part). APP can also be processed by a non-amyloidogenic pathway, where $\alpha$-secretase (red) cleaves APP within the A $\beta$ sequence (dashed box). However, the functions of both APP and its cleavage products are still unclear and under active investigation.

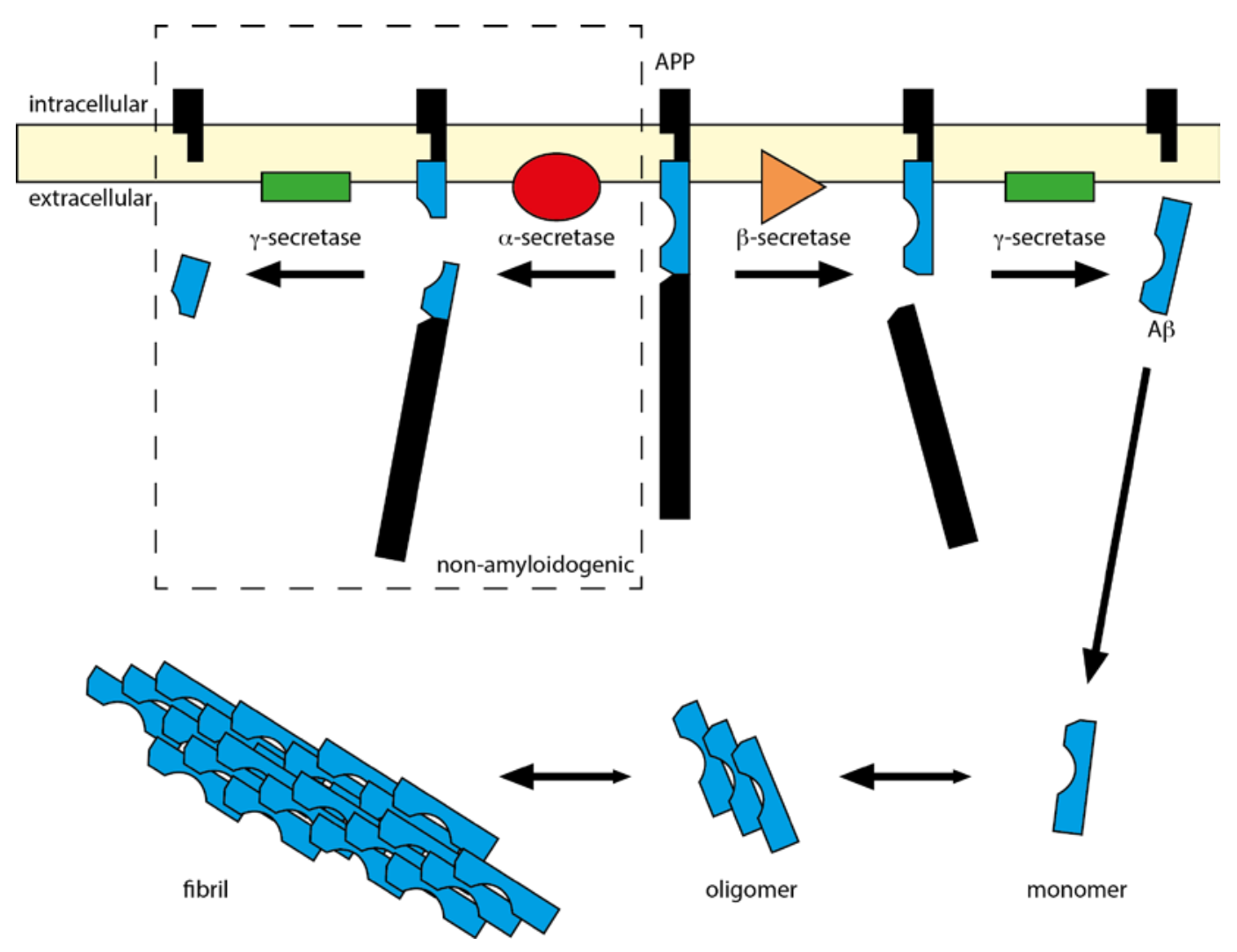

(3) Figure $\mid$ Proteolytic processing of APP and formation of plaques. The transmembrane protein APP can be processed in two ways: 1) In the non-amyloidogenic pathway (dashed box): $\alpha$-secretase (red) cleaves APP within the A $\beta$ sequence (cyan) which prevents release of $A \beta$ upon subsequent cleavage of $\gamma$-secretase (green). 2) The amyloidogenic pathway: if APP is processed by $\beta$-secretase (orange) prior to $\gamma$-secretase, A $\beta$ is released into the extracellular space and can form oligomers and fibrils. 
However, even after more than a century of research, it is still under debate if those macroscopic assemblies, i.e. amyloid plaques and neurofibrillary tangles, are indeed causing neurotoxicity in $\mathrm{AD}$. There are several reports of patients with $\mathrm{AD}$ symptoms but no plaques or tangles, as well as individuals with plaques or tangles but no signs of dementia (e.g. Terry et al., 1991). But it has been rather well established that $\mathrm{A} \beta$ and tau play a central role in $\mathrm{AD}$ pathology. This led to the hypothesis that smaller, soluble assemblies may be the actual toxic forms rather than large, insoluble ones (Viola and Klein, 2015). It is thought that formation of those aggregates may even be a cellular response to counteract the neurotoxicity by sequestering the toxic oligomers in those insoluble deposits. Various studies used a range of techniques trying to identify the toxic species. Different synthetic $A \beta$ species have been investigated in vitro or applied to various cell and animal models to mimic the disease with varying results (Motter, 1995, Georganopoulou et al., 2005, Esparza et al., 2013, Savage et al., 2014).

\subsubsection{Current state of $A D$ diagnosis}

Autopsy is currently still the definite determination of AD. Pre-mortem, the diagnosis of AD is still mainly based on cognitive tests which are performed oftentimes over years and require experienced neurologists (McKhann et al., 2011). Therefore, an alternative diagnosis method is actively searched for that relies on lab results. Currently, the most promising lab-based diagnosis method relies on enzyme-linked immunosorbent assay (ELISA). The protein of interest, $A \beta$ and tau are most commonly used, is immobilized and its concentration is measured using enzyme-linked antibodies. Those enzymes catalyze a chemical reaction that emits light (bioluminescence), which is used to extrapolate the amount of antibodies and therefore the amount of the protein of interest.

Due to their easy accessibility, serum and blood have been used as sample. However, the results are inconclusive (Mayeux et al., 2003, Irizarry, 2004, van Oijen et al., 2006), therefore making cerebral spinal fluid (CSF) the sample of choice. CSF surrounds the central nervous system where it mediates the exchange of metabolites between the central nervous system and the blood circulatory system. Since amyloid plaques are found extracellularly, there is a high chance that the composition of CSF reflects the situation in the brain and therefore can be used as a way to monitor AD development and progression.

Despite promising studies of ELISA using CSF, their results are still under debate (McKhann et al., 2011, Zetterberg and Blennow, 2013). An assay that relies not only on total protein concentrations but also factors in assembly size and structure (i.e. fibrillar, spherical, etc.) should be more precise 
and thus more promising for a new diagnosis method (Fukumoto et al., 2010). In theory, imaging immunostained CSF at high resolution should be able to provide this type of data.

\subsection{Scope of this work}

In this study, I optimized established staining methods in the fields of molecular biology and medical diagnosis for STED microscopy, i.e. fluorescent in situ hybridization (FISH) and immunostaining, respectively. Regarding the former, STED-FISH may shed new light on past issues or provide valuable information on current ones, e.g. on the recently identified circular RNAs (ciRNAs) to help unveiling their function. Imaging methods like FISH may identify or at least exclude functions due to (co-)localization data. Due to the high density of RNAs within cells, the resolution of conventional light microscopy is not sufficient to obtain accurate information about the organization of RNAs. Therefore, I optimized a FISH protocol for STED microscopy to contribute to the investigation of the molecular mechanisms of mRNA distribution and dynamics within cells.

Concerning the field of medical diagnosis, super-resolution - based techniques may contribute to the research on aggregopathies like Alzheimer's disease (AD). Despite decades of research, neither is the exact cause known, nor does a successful therapy exist. The two candidate proteins $A \beta$ and tau have been used as biomarker to develop a diagnosis method, mostly based on ELISA with varying results. There is a need for a reliable, lab-based diagnosis method which, ideally, fulfill all these features: 1) it should be lab-based, i.e. independent from the person doing the experiment; and yield immediate results unlike cognitive tests which may take several years. 2) it should also be able to monitor disease severity since different disease stages might require different treatment. 3) It should be able to predict the disease at prodromal stages, where the patients are still symptom free. Based on those requirements, I approached this problem from a more direct angle. Instead of relying on assays which only determine the concentrations or use rather harsh conditions to investigate those fragile assemblies, I wanted to monitor $A \beta$ and tau particles directly. In principle, this should be feasible by immunostaining and fluorescence microscopy. However, those assemblies are smaller than the diffraction limit of conventional (confocal) light microscopy ( 200 nm). This is why I turned to STED microscopy, which has a resolution limit of $\sim 50 \mathrm{~nm}$ at our microscope. I tried to develop a diagnosis method using super-resolution imaging data of immunostained $A \beta$ and tau in CSF. The STED parameters spot size, spot number, spot intensity, total fluorescence intensity should, in principle, reflect dimensions of the particles, number of particles, how many A $\beta$ or tau 
molecules per particle, and overall protein concentration, respectively. These features then can be used to possibly discriminate AD patients and controls. 


\section{Results}

\subsection{Establishing a FISH protocol for STED microscopy}

Super-resolution microscopy has been mostly applied to studies of protein organization with regard to biological samples. Not only the number of studies identifying new RNA species but also their role in regulating protein expression has been increasing. However, those studies mostly relied on sequencing or biochemical assays. In this work, I refined the fluorescent in situ hybridization (FISH) protocol for STED microscopy I established during my Master's thesis (Zhang, 2011). This does not only allow to localize RNAs but also to monitor their intermolecular organization.

For this approach, I chose to use fluorescently labeled DNA oligonucleotides as probes for the following reasons: 1) DNA probes are easier to handle due to widespread presence of RNases, thereby reducing the risk of degradation of the probes and signal loss. 2) Short probes penetrate cells and tissue easier than long ones. 3) Short probes also enable the use of multiple different probes per target RNA to increase the signal-to-noise ratio. 4) Since the probes are chemically synthesized, the probes have a defined number of fluorophores at defined positions rather than random incorporation of labeled nucleotides during in vitro transcription.

\subsubsection{STED-FISH stains mRNAs specifically}

To check whether the FISH staining was specific, two control experiments were performed. First, cells that do not express the three synaptic proteins synaptophysin, synaptobrevin, and synaptotagmin endogenously were transfected to express the synaptic proteins and stained by FISH. Second, the same mRNAs of the three synaptic proteins were stained by FISH by three different probes, this time not covering the coding sequences (CDSs) but the untranslated regions (UTRs).

Regarding the first control experiment, the transfected cells can be easily identified because they express the synaptic protein fused to a GFP derivate called pHlourin (Figure 4, green). FISH signal could be observed in transfected cells only (Figure $4 \mathrm{~B}$, red). Little signal could be detected in transfected cells using the control probes. The control probes were sense sequences of the target mRNA which was able to detect the double stranded plasmids (Figure 4 A). Untransfected cells identified by the DAPI nuclear staining (blue) showed no FISH signal. 


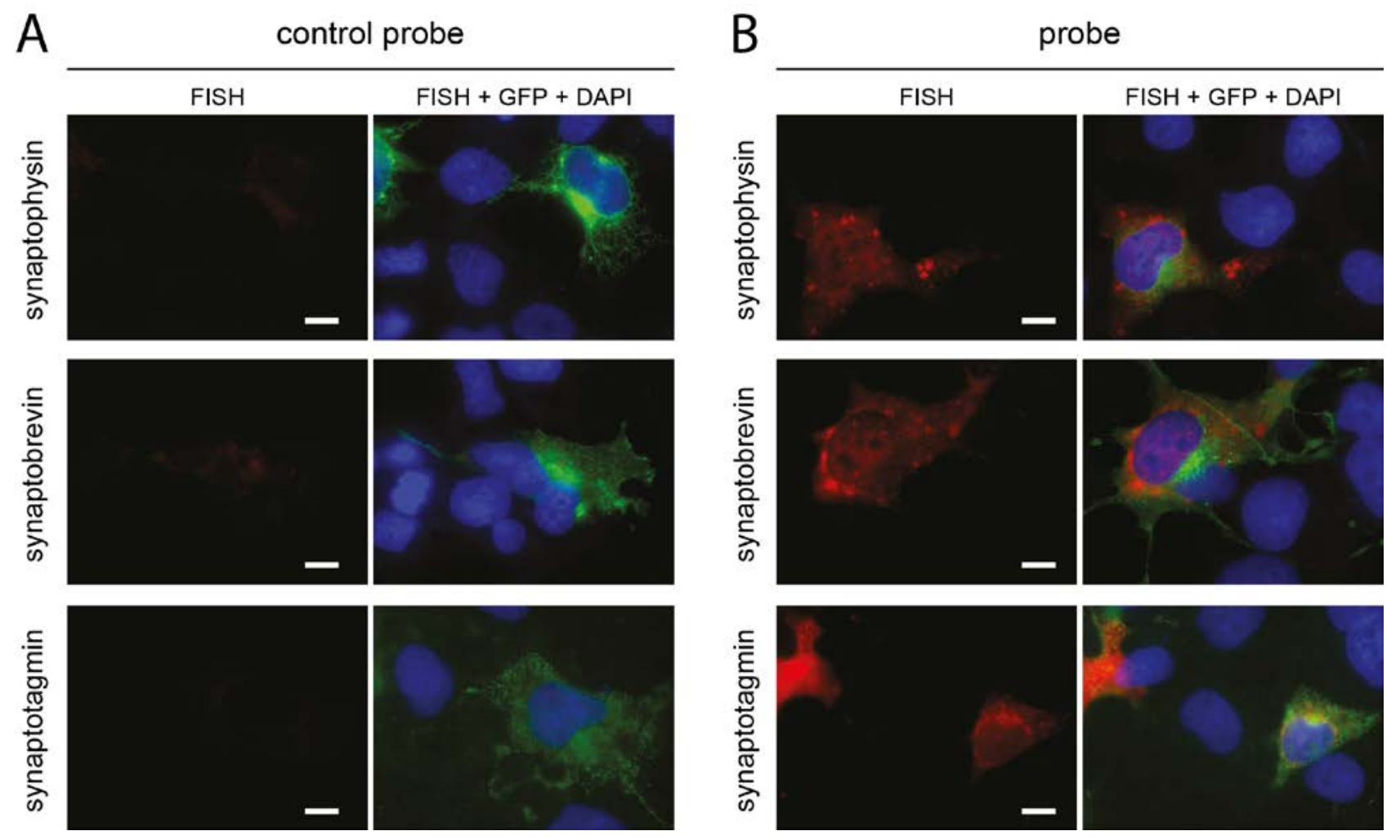

(4) Figure | Cos-7 cells transiently transfected with fusion versions of synaptic proteins. Transfected cells can be easily identified by the GFP signal (green), while untransfected cells are revealed by DAPI staining (blue). (A) Only little signal can be observed within transfected cells when using the control probes (red). The signal originates from specific annealing of the probes to the plasmids that contain both sense and anti-sense sequences of the respective genes. (B) Only transfected cells contain high FISH signal (red). These epifluorescence images were scaled identically for each channel. Scale bars, $10 \mu \mathrm{m}$.

As the other control, I performed FISH to detect the transcripts but this time using a different set of probes against the UTRs of the mRNAs of the three synaptic proteins and compared the staining results of the two sets of probes. The spot densities of both sets were not statistically different from each other (Figure 5) implicating that the staining was indeed specific and reliable.

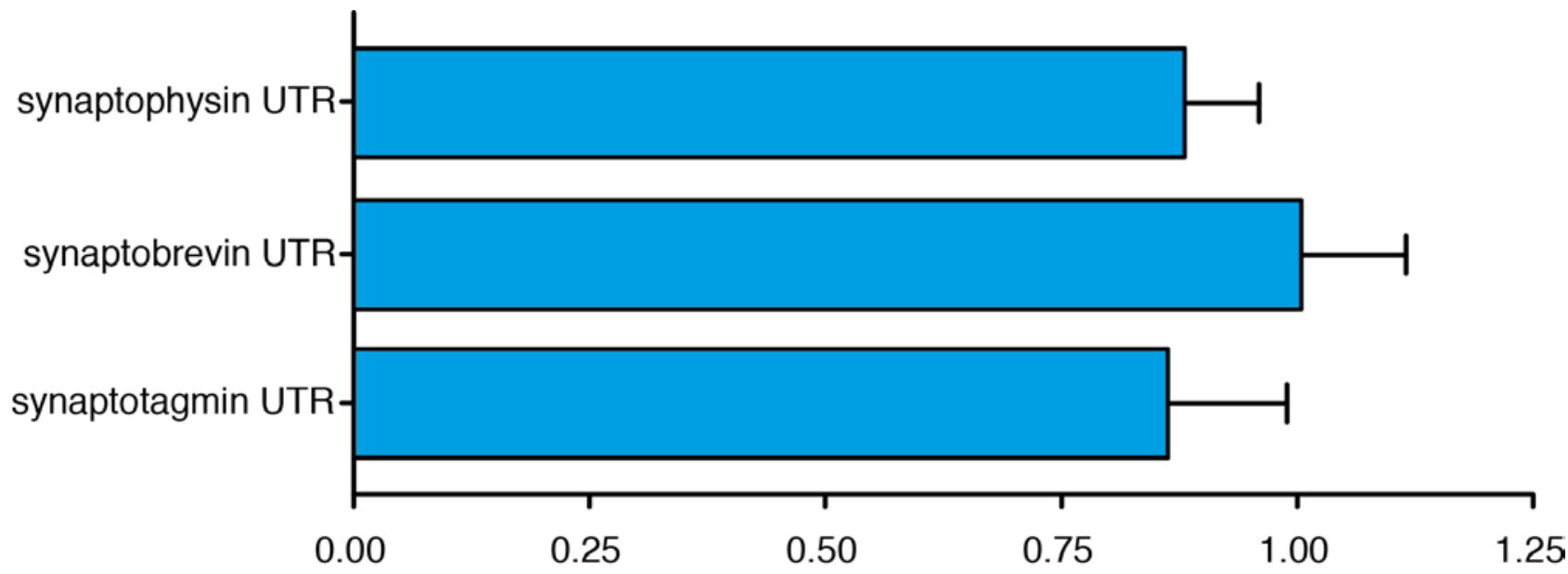

spot density (normalized to the probes against the CDS) 
(5) Figure / Comparison of spot densities between probes targeting the UTRs and CDSs. No statistically significant difference could be seen for any of the mRNAs of the three synaptic proteins ( $\mathrm{n}=5$ to 6 ), suggesting that a representative population was detected.

\subsubsection{Three probes per RNA target are sufficient for reliable detection}

True signal can be discriminated from unspecific binding by fluorescence intensity (Figure 4). Using only one probe was not sufficient to differentiate signal (grey) from background (black). This especially applies for RNAs expressed at low levels, where background might mask the true signal. In contrast, performing FISH with three different probes per RNA target increased the fluorescence intensity per spot significantly allowing reliable identification of the mRNAs (cyan).

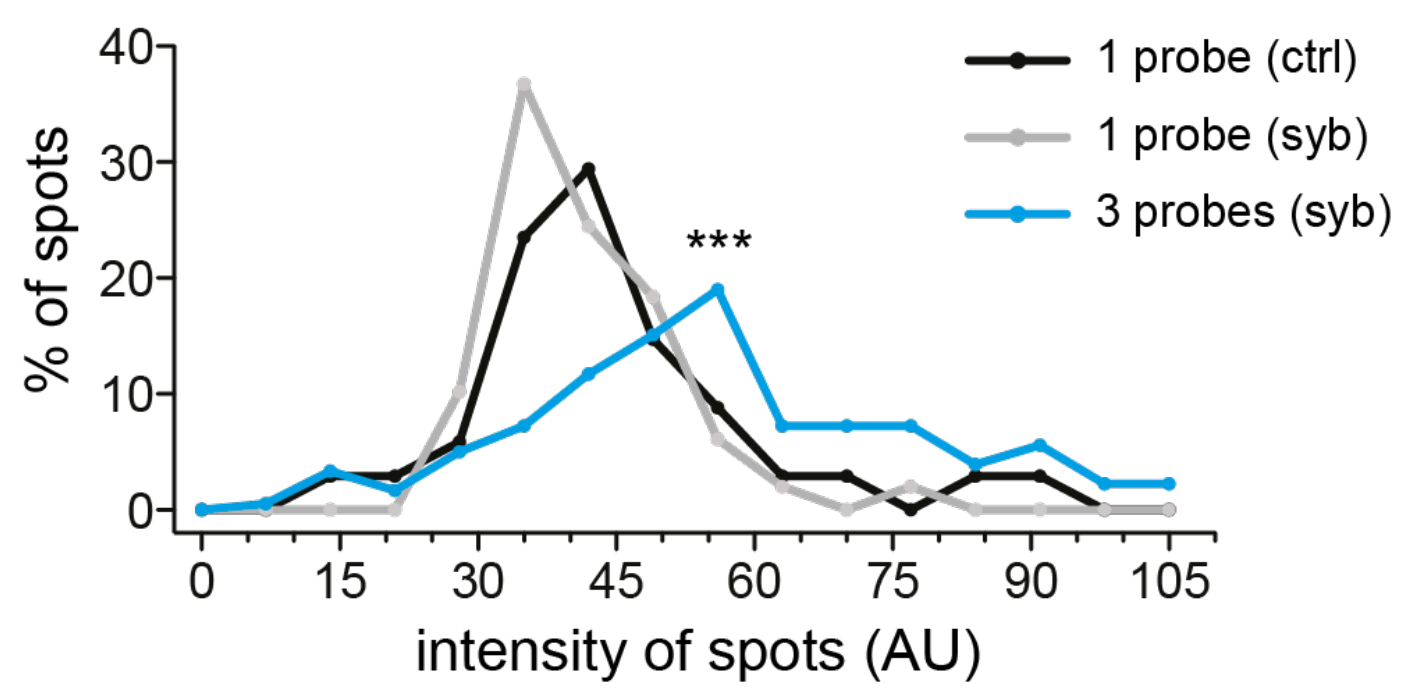

(6) Figure | Histogram of spot intensities with regard to number of probes used. Using only one probe (grey) was not sufficient to reliably distinguish from controls (black). If three probes were used (cyan), the intensity of the majority of the spots was significantly higher than the controls ( $\mathrm{p}<0.001$; t-test).

Since the protocol should be universal for all RNAs (except for very short ones like miRNAs), I decided to use only three probes per RNA. The probes must not overlap to compete for binding sites, nor have cross-reactivity with each other or other transcripts of the sample. This may already be difficult, especially for short RNAs. In the case of synaptobrevin, the three chosen probes were the only possible ones. All probes should be of the same physical properties, so that the hybridization conditions are similar for all probes, i.e length and melting temperature $\left(\mathrm{T}_{\mathrm{m}}\right)$. If mature mRNAs are of interest, the selection criteria are even more strict as the probes should span over adjacent exons. 


\subsubsection{STED-FISH provides information about RNA organization}

I then stained endogenous levels of mRNA of the three synaptic proteins synaptophysin, synaptobrevin, and synaptotagmin in primary hippocampal neurons. Figure 7 shows a neuron identified by synaptophysin immunostaining (cyan). Most of the FISH signal (red) was localized in the cytoplasm of the neuron. Comparison of the confocal and STED images reveal that some of the diffraction limited spots actually consist of multiple spots (cyan circles). This indicates higher numbers of mRNA molecules than apparent in confocal images, making STED more accurate. synaptophysin (IF)

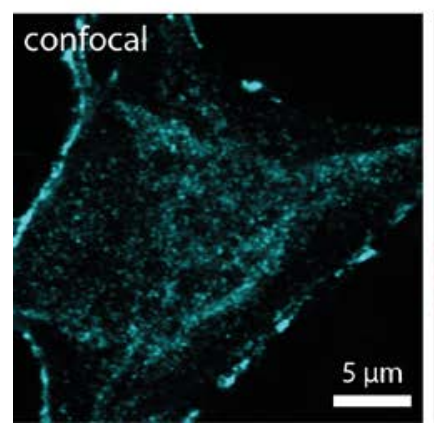

synaptophysin (FISH)

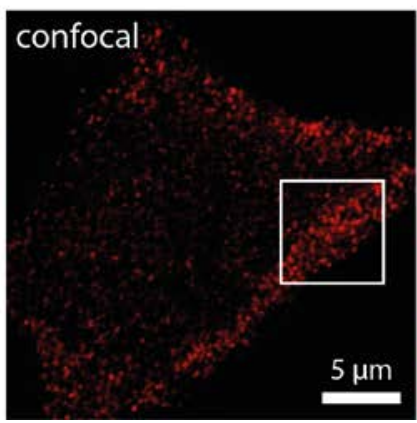

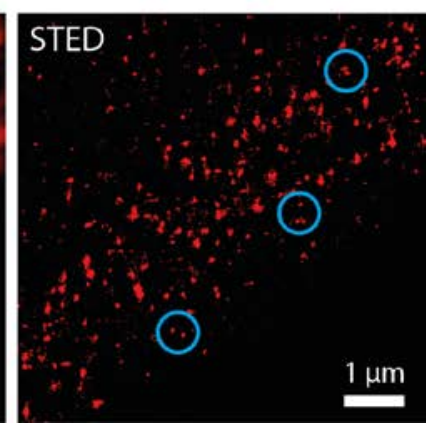

(7) Figure | STED provides more accurate information than confocal microscopy. Confocal and STED images of a neuron stained by immunofluorescence (cyan) and FISH (red) against synaptophysin protein and mRNA. Looking at the zoom-ins (white square), some of the diffraction limited spots in the confocal image consist of multiple spots revealed by STED (cyan circles). Scale bars, $5 \mu \mathrm{m}$ (for overview of neuron) or $1 \mu \mathrm{m}$ (for zoom-ins).

The increased resolution with STED-FISH did not only allow a more precise estimation of the mRNA numbers but also provided information about the intermolecular organization. The spots of the three synaptic proteins were approximately $~ 50-60 \mathrm{~nm}$ in size, i.e. at the resolution limit of the STED microscope used for this work (Figure 8, first three panels). In contrast, the spots of $\beta$-actin mRNA were noticeably larger and brighter ( $\sim 0 \mathrm{~nm}$, right panel), suggesting an organization in structures containing multiple mRNA molecules. 

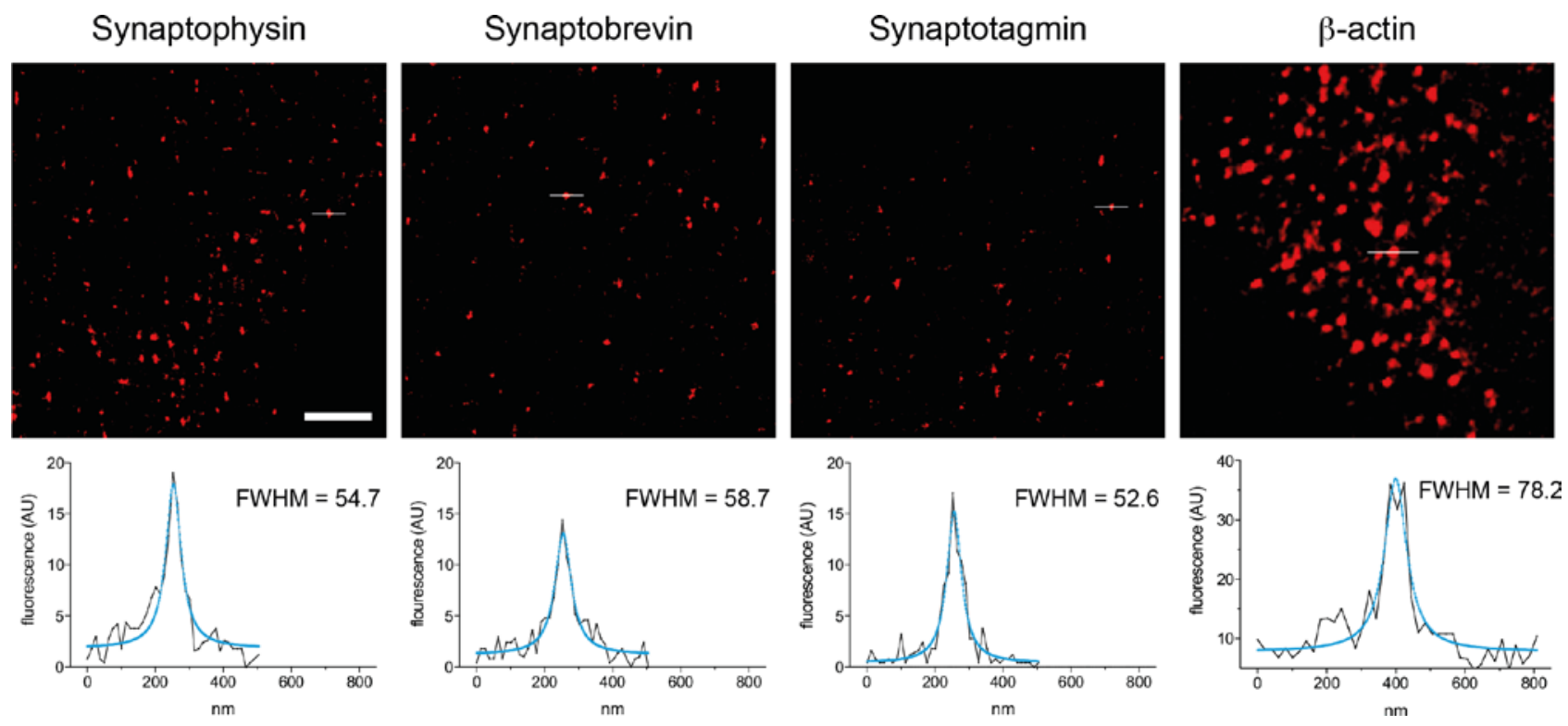

(8) Figure | STED-FISH is able to resolve mRNA organization. STED images of neurons stained by FISH against the mRNAs of synaptophysin, synaptobrevin, synaptotagmin, and $\beta$-actin (upper panel) and the respective line scans (white lines in the images, graphs in the lower panel). While the spot sizes of the three synaptic proteins was close to the resolution limit of our microscope ( $\sim 50-60 \mathrm{~nm}$; first three columns), $\beta$-actin showed larger spots $(\sim 80 \mathrm{~nm}$; fourth column). Also note the scaling of the y-axis, showing approximately double the fluorescence intensity for $\beta$-actin. Scale bar, $1 \mu \mathrm{m}$.

\subsubsection{STED-FISH is able to monitor mRNA levels qualitatively}

FISH can monitor RNA levels qualitatively based on the spot number in relation to the volume of the cell. This type of quantification may not be as accurate as biochemical assays like quantitative PCR (qPCR). Those methods, however, usually require more material (i.e. cells). mRNA levels of the three synaptic proteins and of the general housekeeping protein $\beta$-actin were investigated with regard to neuronal development in vitro. The mRNAs, as measured by spot density, of all four proteins increased with maturation (Figure 9; cyan, red, green, and yellow), while the spot density of the control probes remained at the baseline (black). Interestingly, synaptophysin showed the largest relative change until day in vitro (DIV) 21 and reduced the expression thereafter. 


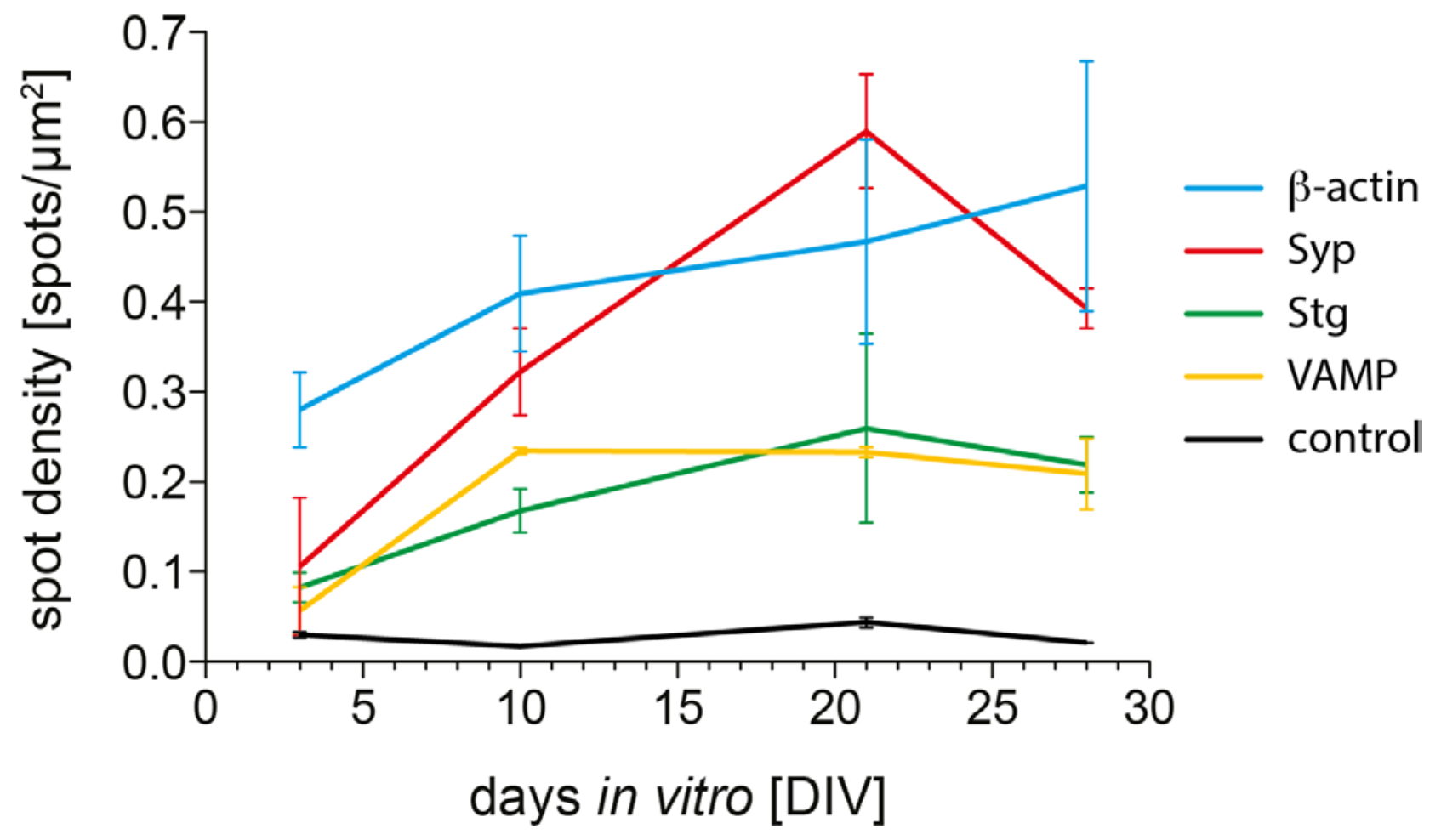

(9) Figure | Changes in mRNA levels with respect to age in vitro. The numbers of mRNA molecules for $\beta$-actin and the three synaptic proteins increase with age while the control stayed on the baseline level. Interestingly, the spot density of Syp FISH (red) increased 5fold until DIV 20 and decreased to the 4-fold of the initial level at DIV 28.

\subsection{Establishing a microscopy-based diagnosis method for AD}

Despite Alzheimer's disease (AD) being the most common form of dementia, its diagnosis mainly relies on cognitive tests. This means that the patients already show symptoms of cognitive impairment at the time of diagnosis, due to potential neuronal damage possibly caused by abnormal $\mathrm{A} \beta$ and/or tau assemblies (Andreasen and Blennow, 2005). Therefore, I turned to STED microscopy analyzing $A \beta$ and tau assembly numbers and sizes in human CSF to develop a novel diagnosis method. Compared to only analyzing their concentrations in CSF or the cognitive states of the patients, my approach might 1 ) diagnose the disease more reliably and with higher accuracy. STED is able to additionally provide information about particle size and organization, which is thought to be a major factor of the neuronal toxicity (oligomers vs insoluble fibrils, also see Section 1.4); 2) detect the disease at prodromal stages when toxic $A \beta$ and tau species have formed but have not affected the patients cognition; and 3) monitor disease severity and thus disease progression.

To characterize A $\beta$ and tau assemblies, I analyzed human CSF samples of 36 AD patients, 21 controls, and 11 mild cognitive impaired (MCIs). The underlying idea was to immobilize CSF on 
coverslips, immunostain for $A \beta$ and tau, and to analyze their assembly characteristics by STED imaging (Figure 10).

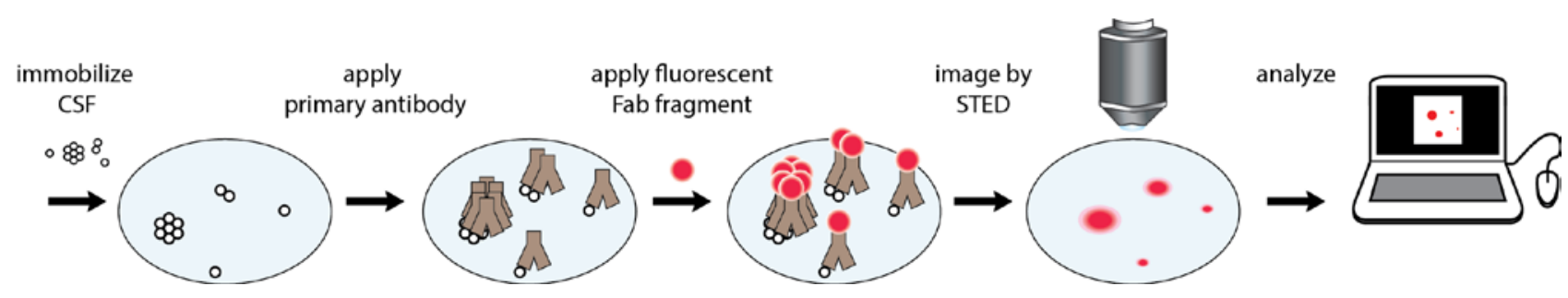

(10) Figure | Schematic overview of the experimental procedure. PLL coated coverslips were incubated with CSF. The samples were then fixed and immunostained using primary antibodies and secondary Fab fragments conjugated to Atto647N. The images obtained by STED imaging were analyzed by a custom-written MatLab macro.

\subsubsection{Optimization of coverslip coating and fixation}

The first challenge was to immobilize the proteins present in the CSF on coverslips for immunostaining. This procedure needs to fulfill several criteria: 1) The proteins need to be immobilized on the coverslip to endure the immunostaining procedure. 2) The procedure should represent the CSF in protein composition and organization. Especially in the case for $A \beta$, it is known that even at room temperature aggregates may form (Zimmermann et al., 2011). Therefore, the fixation should be as short as possible to avoid artifacts. 3) It should not interfere with the antibody recognition. Some fixatives like glutaraldehyde are known to change the epitopes so that antibodies cannot bind to their targets (Shtengel et al., 2014). I tested four coating agents and four fixation solutions for the best immunostaining result. The combination of PLL coating and 4\% PFA fixation (Figure 11, cyan square) achieved the most signal, implying that most material was fixed to PLL by 4\% PFA only and that the fixation procedure did not interfere with the antibody recognition. It was therefore used for all subsequent experiments. 


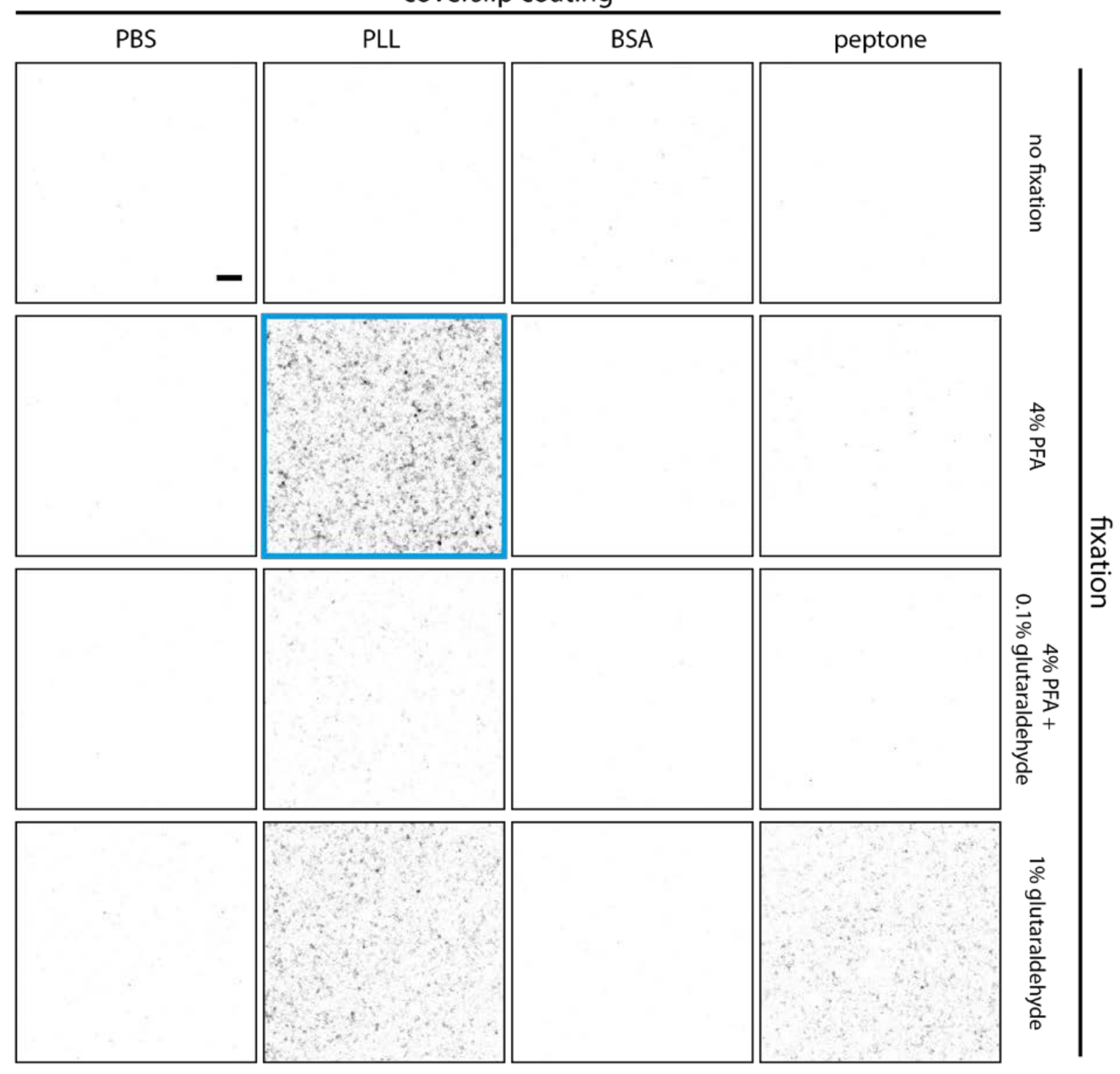

(11) Figure | Epifluorescence images of coating and fixation optimization. I tested four conditions each for coating (PBS, PLL, BSA, or peptone) for a suitable substrate and for fixation (no fixative, PFA, PFA and glutaraldehyde, or glutaraldehyde) to immobilize the CSF onto the coverslips. The combination of PLL coating and fixation with 4\% PFA yielded the most immunofluorescence (cyan square). Colors inverted for better visibility. Scale bar, $2 \mu \mathrm{m}$. 


\subsubsection{Antibody selection and blocking}

As for all immunostainings, the staining conditions need to be optimized for each antibody and sample type. Different antibodies bind to different epitopes with different affinities, which in turn affects the level of blocking needed to avoid poor signal-to-noise ratio or even artifacts. This is especially critical for immunostaining CSF since there are no structures for orientation as for cells or tissue samples. I tested nine different antibodies against different $A \beta$ species, since the toxic $A \beta$ isoform is still under debate; four against different tau versions, some of them against phosphorylated forms, since neurofibrillary tangles have been found to contain hyperphosphorylated tau proteins; as well as two oligomer-specific antibodies to detect only the potentially toxic species (see Section 4.4 for complete antibody list).

Blocking solutions for antibody stainings typically contain proteins that do not interfere with the antibody recognition to compete with the antibodies for any unspecific binding. Different blocking solutions with different blocking agents at varying amounts of protein were tested for each antibody. To test the background, only coverslips incubated with BSA instead of CSF were used (negative control), since it should be free of epitopes and therefore show only little signal. Figure 12 shows the blocking optimization for a selection of four antibodies. The 6E10 and the pan tau antibody are thought to detect all forms of A $\beta$ and tau, respectively, while ab10148 and ab12267 were reported to only recognize specific $A \beta$ species (see Section 4.4 for details).

Similarly to numerous other previous studies on A $\beta$ in human CSF (e.g. Pirttilä et al., 1994, Maddalena et al., 2004), 6E10 was selected for the investigation due to its high sensitivity. Its property to potentially detect all $A \beta$ species might allow the acquisition of a more complete protein profile of the CSF. Similarly, I chose the pan tau antibody for investigation of the tau CSF contents. Other antibodies were not used for further experiments due to poor staining results. 


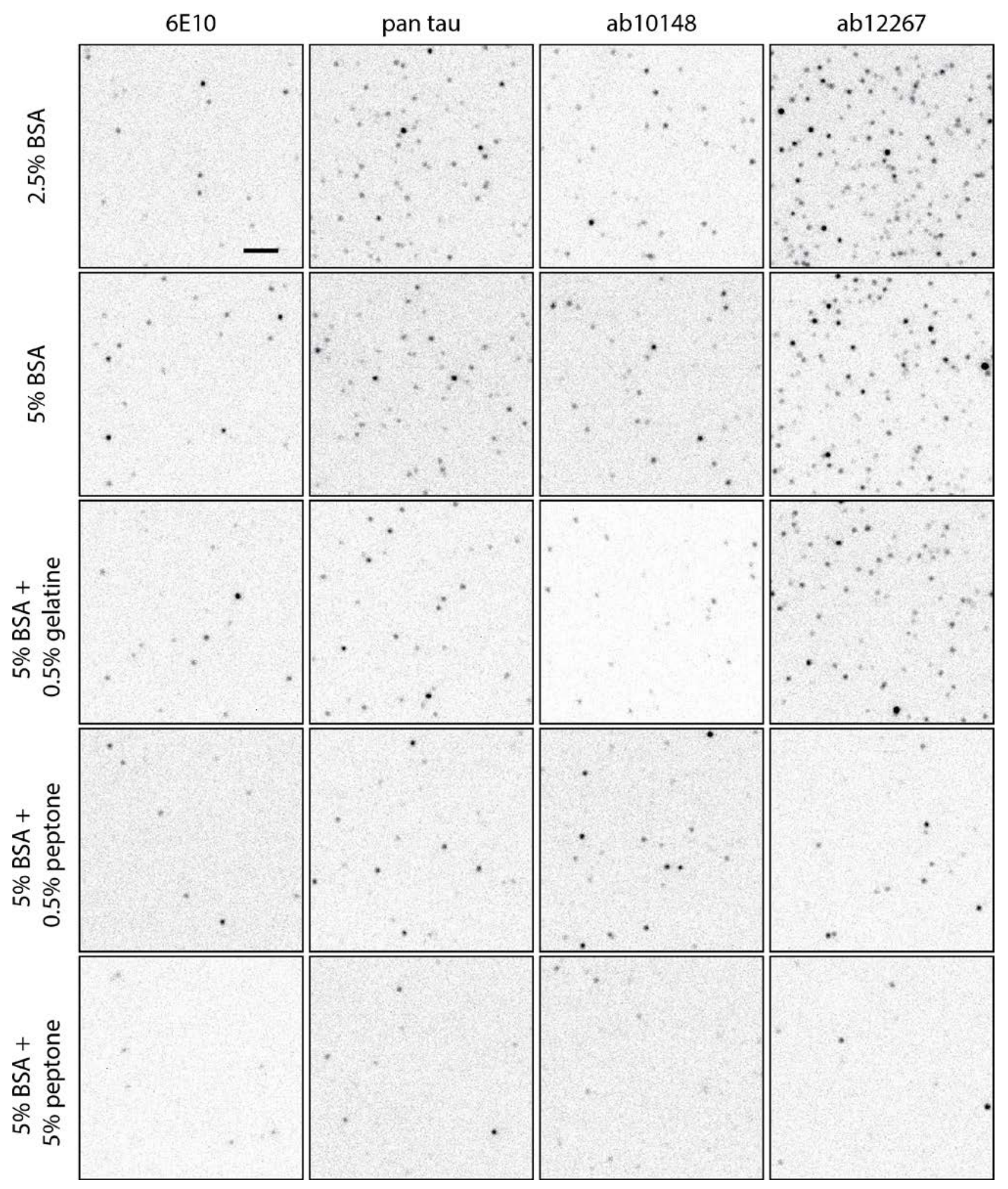

(12) Figure | Epifluorescence images of the optimization of blocking conditions. Coverslips were incubated with BSA only instead of CSF (negative control) and immunostained as described in Methods using different blocking solutions. Using the strongest blocking (5\% BSA plus 5\% peptone) obtained the fewest unspecific staining and was therefore used for all experiments. All images were scaled identically. Images were inverted in color to provide better visual representation. Scale bar, $2.5 \mu \mathrm{m}$. 


\subsubsection{Super-resolution is able to separate assemblies of different sizes}

Confocal images of CSF immunostained against $A \beta$ showed many spots with many of them touching or overlapping each other. Imaging the same samples with STED provides more accurate information due to the increased resolution. Similar to STED-FISH (Figure 7), some diffraction limited spots in the confocal images actually consisted of multiple individual spots which offered more precise numbers of $\mathrm{A} \beta$ assemblies (Figure $13 \mathrm{~A}$, red circles). In addition, a line scan over the same representative spot imaged in confocal and STED mode (cyan circle) showed the resolution limits of both techniques ( 277 $\mathrm{nm}$ for confocal and $\sim 45 \mathrm{~nm}$ for STED, Figure $13 \mathrm{~B}$ ). The higher resolution of STED may help to identify the size of the toxic species.
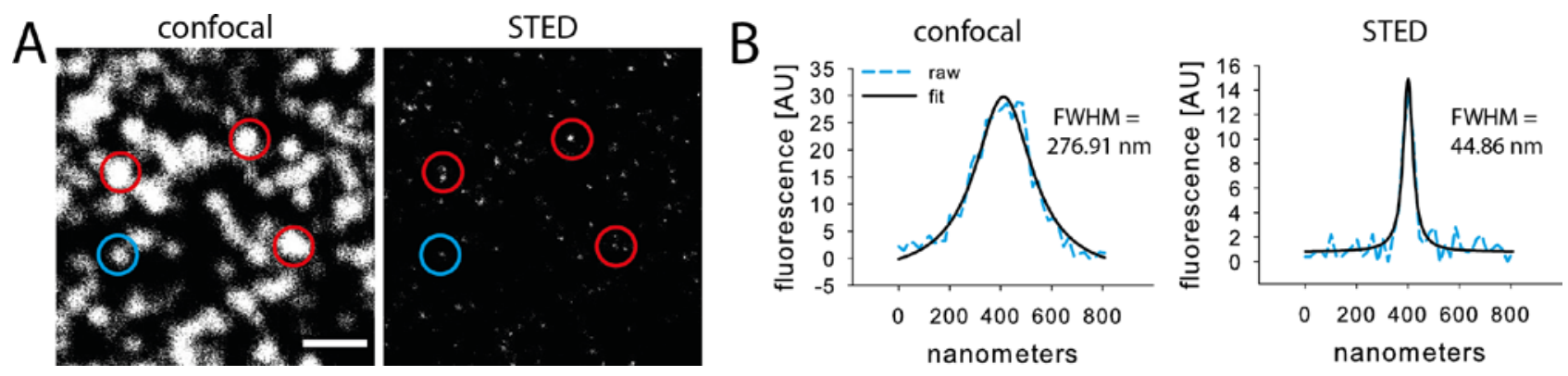

(13) Figure / Comparison of immunostained CSF imaged by confocal and STED microscopy. (A) CSF was immunostained as described in Methods and imaged in confocal (left) and STED (right) mode. The increased resolution of STED offers more details about the composition of $A \beta$ assemblies in the CSF. With confocal, all three spots highlighted by the red circles can only be identified as one spot. In contrast, STED is able to resolve them originating from multiple or one single, bright object. (B) Raw (cyan) and fitted (black) line scans of the same individual spot (cyan circles in panel A). Confocal microscopy is limited by diffraction and thus is only able to resolve object to $\sim 250 \mathrm{~nm}$ (full width of half maximum, FWHM) while STED can differentiate spots which are $\sim 25$ times smaller (FWHM of $50 \mathrm{~nm}$ in both $\mathrm{x}$ - and y-dimension). Scale bar, $1 \mu \mathrm{m}$.

Next, to test whether STED is indeed capable of discriminating assemblies of different sizes, I immunostained low- (LMW) and high-molecular weight (HMW) assemblies of in vitro synthesized A $\beta$ peptides. LMW A $\beta$ showed small spots of similar sizes, while HMW A $\beta$ showed spots of different sizes with many remarkably larger than for LMW A $\beta$ (Figure 14 A). Analysis of the STED images showed a clear difference between the two samples (Figure 14 B). LMW A $\beta$ spots were smaller and dimmer (indicating fewer $A \beta$ molecules per spot) than HMW A $\beta$ spots. Assembly sizes were determined by size exclusion column (for details, see Section 4.8.1.). 

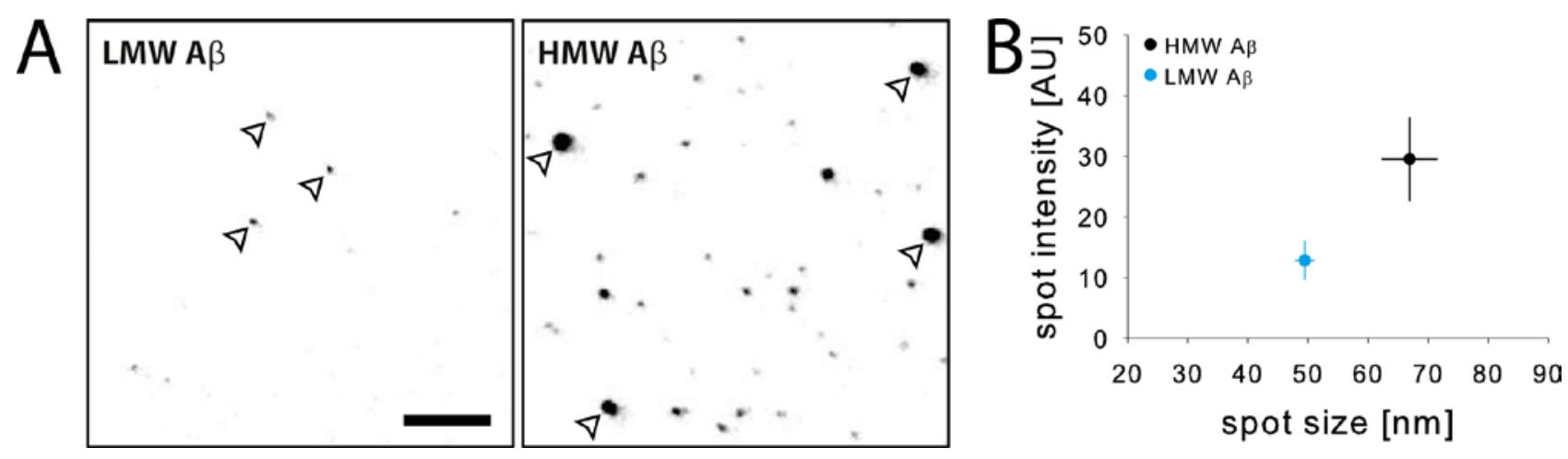

(14) Figure | STED assessment of low (LMW) and high molecular weight (HMW) A $\beta$ assemblies produced in vitro. (A) Representative STED images of synthetically produced LMW (left) and HMW A $\beta$ assemblies (right). Colors were inverted for better visibility. Scale bar, $1 \mu \mathrm{m}$. (B) The quantification shows that the two $\mathrm{A} \beta$ species can be discriminated from each other by either spot size or intensity. Note that the mean spot size of the LMW assemblies is close to the resolution limit of the microscope. Graph shows means \pm SEM.

These results show that I successfully established an immunostaining protocol for $A \beta$ and tau of human CSF for STED microscopy capable of discriminating assemblies of different sizes.

\subsubsection{AD patients show fewer, smaller, and dimmer spots than controls}

CSF samples from 36 AD patients, 21 controls, and 11 MCI were immunostained for A $\beta$ and tau, imaged by STED, and analyzed as described in Methods. Figure 15 A shows representative STED images of CSF samples from controls (upper panel) and AD patients (lower panel) immunostained for $A \beta$. Intriguingly, AD patients showed fewer, smaller, and dimmer spots (Figure $15 \mathrm{~B}$ ). This may be accounted by sequestration of $A \beta$ peptides into amyloid plaques in the brain, thereby reducing the amount of CSF $A \beta$. 

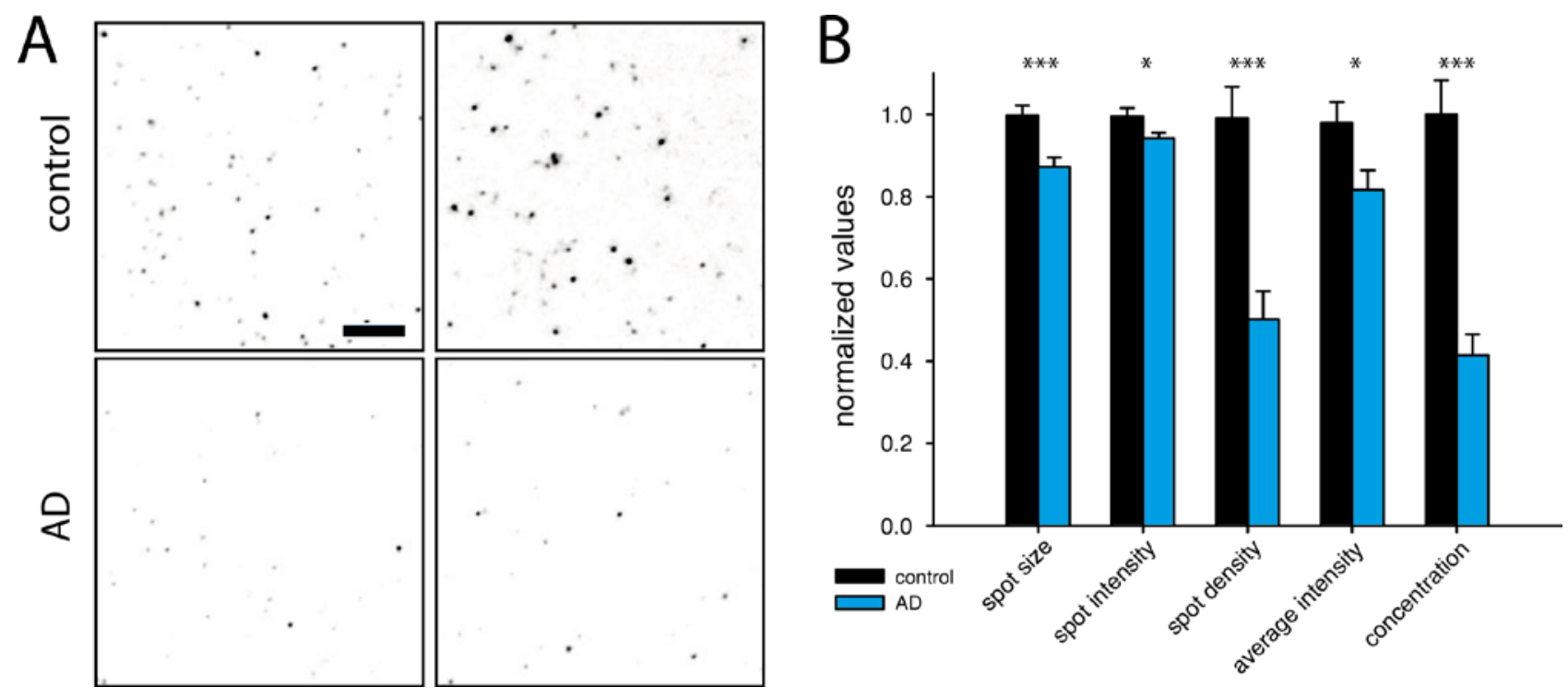

(15) Figure | Analysis of CSF A $\beta$ by STED imaging. (A) Example STED images of CSF immunostained for $\mathrm{A} \beta$. AD patients (lower panel) show smaller and fewer spots than controls (upper panel). Images were color inverted for better visibility. Scale bar, $1 \mu \mathrm{m}$. (B) Bar graph of the mean values of the four STED parameters (spot size, spot intensity, spot density, and average intensity) and $A \beta$ concentration determined by ELISA. Controls show statistically significant higher values than AD patients for each parameter $(*<0.05$; $* * *<0.001)$.

\subsubsection{STED parameters of tau increased prediction accuracy}

With the means of all four parameters (spot size, spot intensity, spot density and overall intensity) being significantly different in AD patients and controls (Figure $15 \mathrm{~B}$ ), I analyzed CSF samples with regard to tau (Figure 16). Despite none of the STED parameters being significantly different between $\mathrm{AD}$ patients and controls (Figure $16 \mathrm{~B}$ ), combination of $\mathrm{A} \beta$ and tau data increased prediction accuracy from approximately $76 \%$ for both sensitivity and specificity to $79 \%$ and $87 \%$, respectively (Figure $16 \mathrm{C}$-E), with sensitivity defined as the percentage of AD patients that were correctly identified and specificity defined as the percentage of controls that were correctly identified. The underlying discriminator functions $\mathrm{F}(\mathrm{A} \beta)$ and $\mathrm{F}(\mathrm{A} \beta$, tau) were obtained by combining all four parameters in a linear equation (Equation III and IV). Finally, the STED values $\mathrm{F}(\mathrm{A} \beta)$ and $\mathrm{F}(\mathrm{A} \beta$, tau) correlate well with ELISA measurements of $\mathrm{A} \beta$ (Figure 17). 

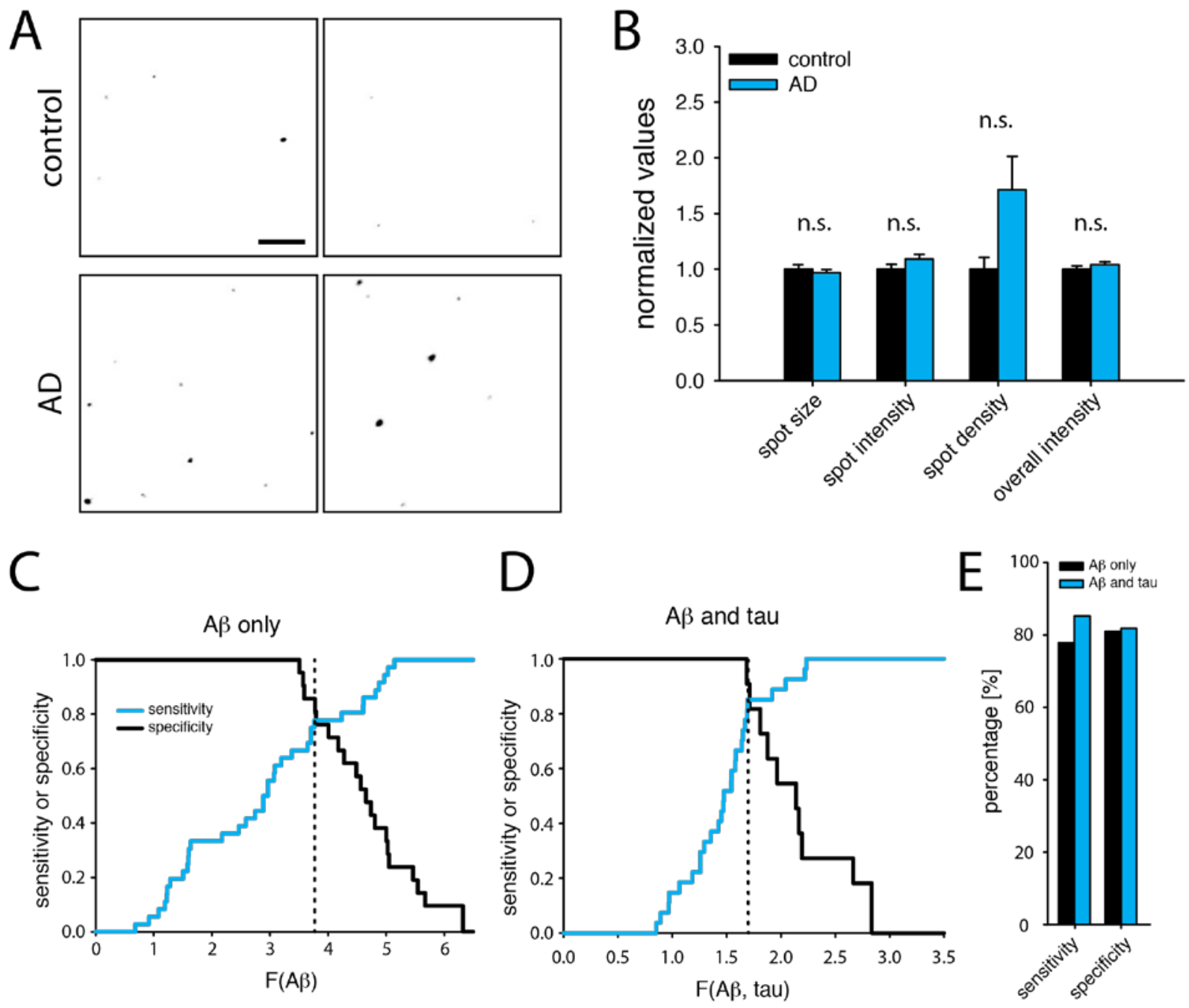

(16) Figure | Analysis of CSF tau by STED imaging and prediction accuracy of STED. (A) Representative STED images of CSF immunostained for tau. AD patients tend to show more spots. Images were color inverted for better visibility. Scale bar, $1 \mu \mathrm{m}$. (B) Bar graph of the mean values of the four STED parameters (spot size, spot intensity, spot density, and average intensity). Differences in neither of the four parameters were statistically significant (n.s.) (C) Prediction accuracy of the STED-based assay according to the cut-off for the $F(A \beta)$ value or (D) $F(A \beta$, tau) value (dashed lines). (E) Improved prediction accuracy when $A \beta$ and tau data is combined (cyan) compared to $A \beta$ alone (black). 
$F_{A \beta}=a \cdot \frac{A \beta_{\text {spotsize }}}{A \beta_{\text {spotintensity }}}+b \cdot \frac{A \beta_{\text {spotdersity }}}{A \beta_{\text {totalimageintersity }}}$

(III) Equation $\mid$ Discriminator function using STED parameters from $\mathrm{A} \beta$ data. This equation assigns a value to each patient according to the STED parameters for $A \beta$, where a and $b$ are constants and b surpasses a by 3-4 fold. Best separation of AD and controls was achieved with a cut-off value of $\sim 3.7$.

$F_{\text {AG,tau }}=a \cdot \frac{A \beta_{\text {spoxsize }}}{A \beta_{\text {spotintenaity }}}+b \cdot \frac{A \beta_{\text {spatdersity }}}{\text { tau spotintensity }}$

(IV) Equation | Discriminator function using STED parameters from A $\beta$ and tau data. This equation assigns a value to each patient according to the STED parameters for $A \beta$ and tau, where $\mathrm{a}$ and $\mathrm{b}$ are constants and both left at 1 . Best separation of $\mathrm{AD}$ and controls was achieved with a cut-off value of $\sim 1.7$.
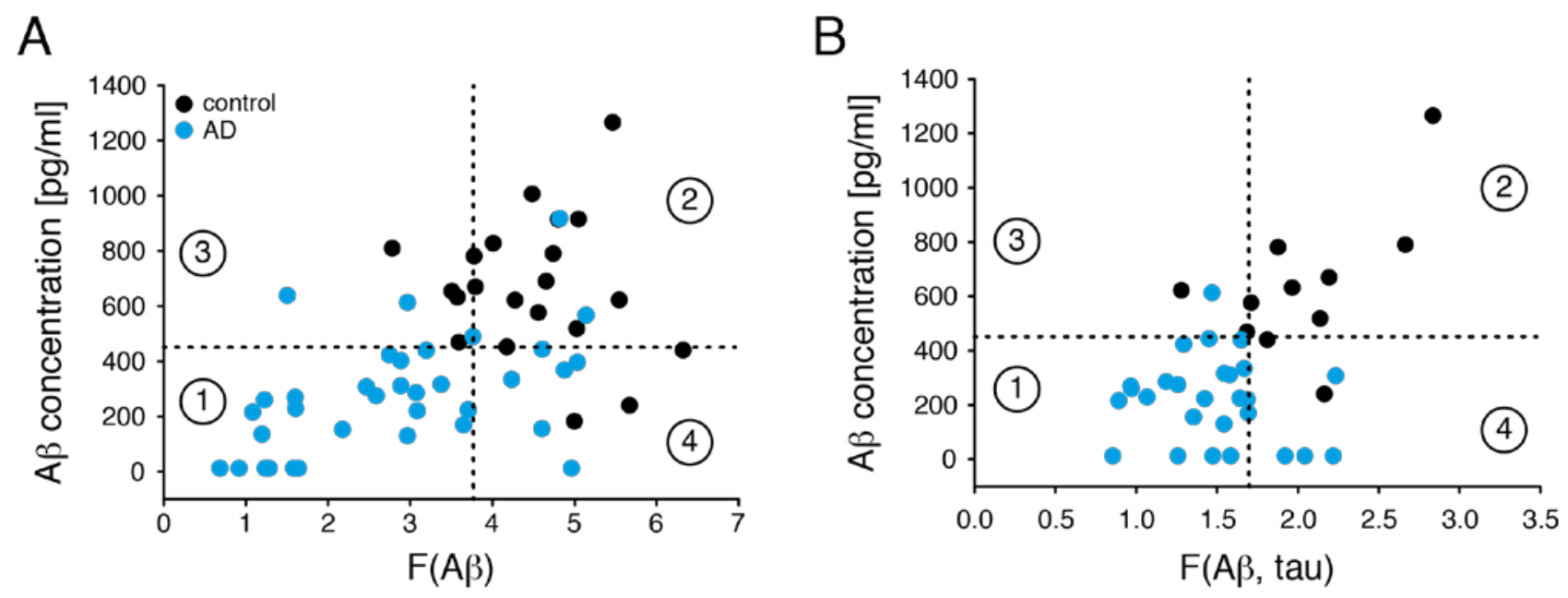

C

$\mathrm{D}$
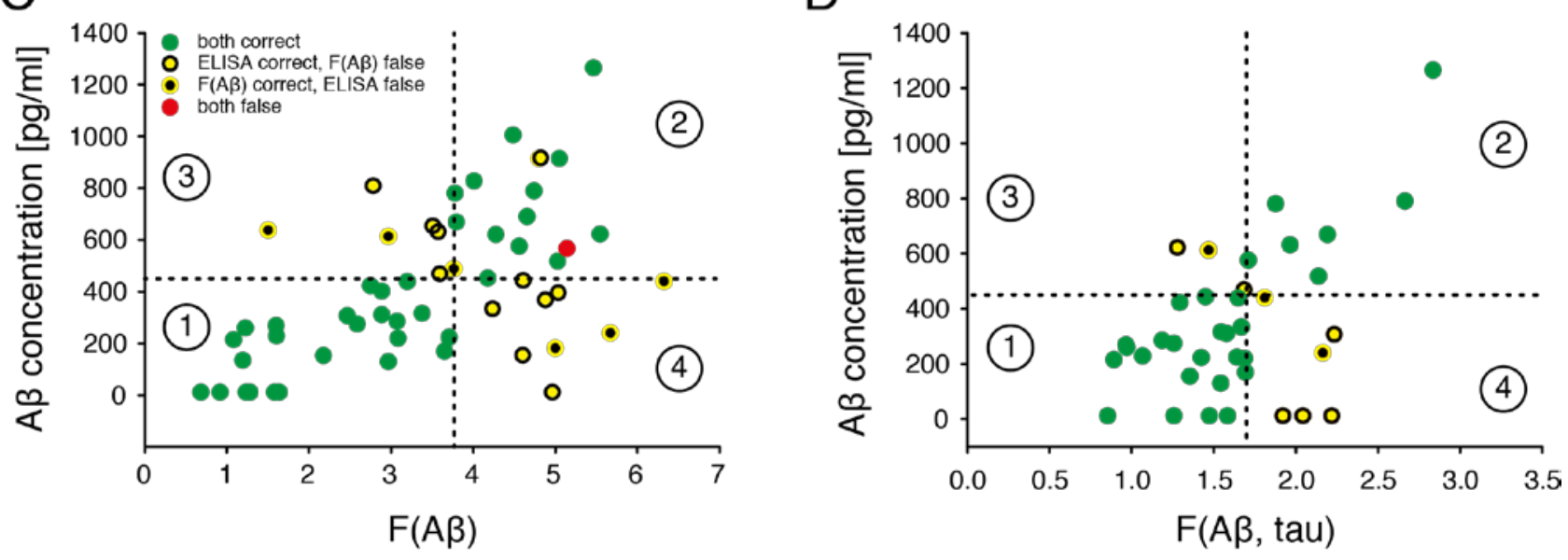

(17) Figure / Comparison of STED and ELISA prediction accuracies. (A) F(A $\beta$ ) values and (B) $\mathrm{F}(\mathrm{A} \beta$, tau) values are plotted on the $\mathrm{X}$-axis against $\mathrm{A} \beta$ concentrations determined by ELISA on the Y-axis; controls are displayed in black, AD patients in cyan. The dotted lines indicate the cut-off values used to separate AD patients from controls at $450 \mathrm{pg} / \mathrm{ml}$ for ELISA and 3.77 for $F(A \beta)$ or 1.70 for $F(A \beta$, tau), respectively. The four regions within 
the graphs represent: (1) patients identified as controls by both ELISA and STED; (2) patients identified as AD by both techniques; (3) patients identified as controls by ELISA but as AD by STED; (4) patients identified as AD by ELISA but as controls by STED. It is evident that most patients fall into the areas (1) and (2) indicating identical prediction by both techniques for the majority of the patients. (C-D) For graphic view of identification accuracies, the same graphs are displayed color-coded as indicated in the legend. The green dots dominate indicating that both techniques identified most of the patients correctly.

\subsubsection{STED parameters of two MCI patients were within AD range}

The same method was applied to patients with mild cognitive impairment (MCI, see Section 4.8.3.). Two of the MCI patients developed full AD during the course of the study and were placed close to the AD average of the STED assay (Figure 18). This indicates that STED might have the capability to predict $\mathrm{AD}$ at prodromal stages.
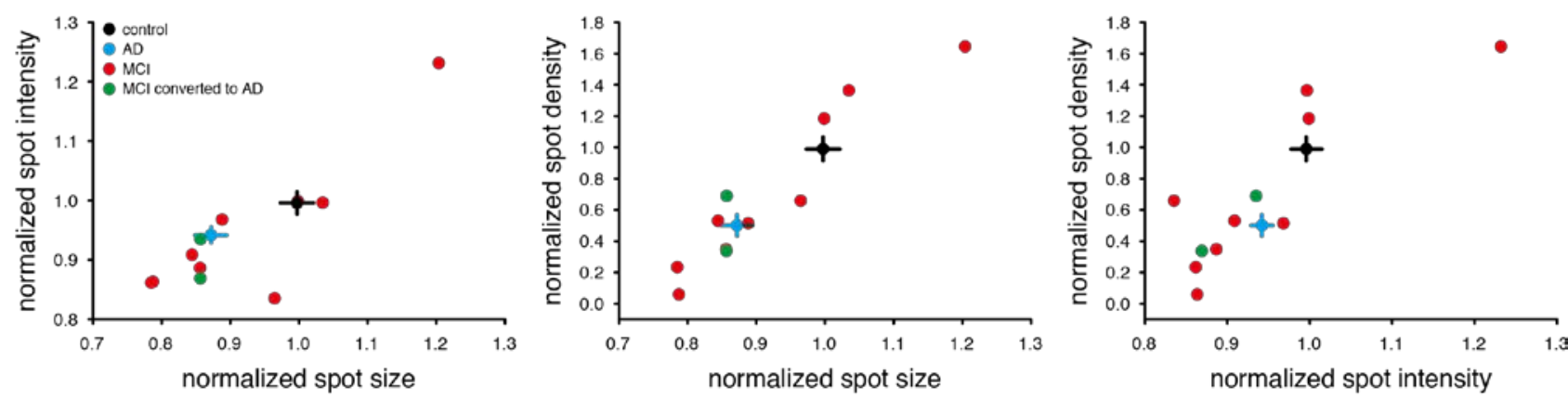

(18) Figure | STED values of MCI patients with respect to the averages of AD patients (grey) and controls (black). MCI patients are indicated by red dots, with the two MCIs that converted to full AD during the study which are depicted in green. Note that the green dots are close to the $\mathrm{AD}$ average (cyan). 


\section{Discussion}

In this work, I have applied STED microscopy - as a representative for super-resolution microscopy techniques - to two applications: fluorescent in situ hybridization (Section 2.1) and diagnosis of Alzheimer's disease (Section 2.2). Due to the increased resolution of STED, the methodologies needed to be optimized for the needs. This works shows that using STED with well established methods provides more accurate information compared to conventional confocal microscopy. For both cases, STED was able to reveal multiple spots per individual diffraction limited spot. This allowed to characterize mRNA levels and organization of the synaptic proteins synaptophysin, synaptobrevin, and synaptotagmin and the housekeeping protein $\beta$-actin more accurately than by conventional light microscopy (Section 2.1.3.). $\beta$-actin mRNA seems to be organized in units of multiple RNA molecules as those particles were larger and brighter compared to the spots of the synaptic proteins (Figure 8).

This first application of super-resolution microscopy to medical diagnosis was able to discriminate controls from AD patients by analyzing images of immunostained CSF samples. The assay uses the parameters number and size of assemblies and number of $A \beta$ or tau molecules per assembly, which allowed a separation with a specificity of $\sim 87 \%$ and a sensitivity of $79 \%$ (Figure 16). This accuracy is comparable to the one achieved by ELISA, the current gold standard in the field. In addition, two of the MCIs who converted to full AD during the study showed similar A $\beta$ profiles as AD patients (Figure 18). Despite being only a very small sample size, these side findings encourage for further investigations.

\subsection{Technical limitations}

Both applications posed a particular challenge compared to other targets or sample types, like organelle marker or cell culture systems. In both cases in this study, the stainings were difficult to be confirmed by structure, since the images consisted of seemingly random spots. For staining and imaging CSF, there is only a single layer of molecules to be imaged, which adds to the difficulty. Due to the low amount of material, there is only little fluorescence in the first place, thereby decreasing the signal-to-noise ratio and resolution. In addition, drifting might cause not only reduction of the signal but even loss of the initially low fluorescence. 


\subsection{Technical limitations of FISH}

\subsubsection{Loss of RNA}

Another issue is the loss of RNAs during the experimental procedure. For one, contaminations with widespread present RNases may degrade a large percentage of RNAs, including the target mRNA and thereby reducing the FISH signal. Second, the fixative PFA fixes cells mainly based on crosslinking proteins. Due to repeated washings under harsh conditions (i.e. formamide and temperatures well above room temperature) non-proteinaceous molecules like RNAs may be lost and can therefore not be detected by FISH. The issue of signal loss can be exacerbated by masking of the binding sites for the probes on the mRNA molecules by translating ribosomes or other RNAbinding proteins.

\subsubsection{Inefficient blocking}

Many blocking solutions for in situ hybridization protocols include sheared Salmon sperm DNA to block unspecific binding of the probes. These random sequences compete with the probes with DNA/RNA-binding proteins, other nucleic acids, and other unspecific interactions due to the same nature. However, its blocking capabilities may be suboptimal due to its size. According to different manufacturers, the size of most DNA molecules is larger than $1000 \mathrm{bp}$, which is $\sim 2-5 \mathrm{x}$ the size of in situ hybridization RNA probes and $20-50 x$ of DNA probes. The cytosol is densely filled with protein which are cross-linked by fixation. Considering that one nucleotide is generally larger than one amino acid, it seems quite plausible that many unspecific binding sites of the probes are not blocked by the Salmon sperm DNA because they cannot reach the binding sites the probes can due to their size. To alleviate this issue, I used Salmon sperm DNA that has been further processed by sonication to sizes around 200 bp by the lab of Andre Fisher, DZNE, Göttingen, Germany.

\subsubsection{Signal amplification}

In principle, weak signal could be amplified by increasing the number of probes per target, by increasing the number of fluorophores per probe, and/or by using indirect labeling. Increasing the number of probes per target may be difficult to achieve. Designing probes for transcripts that are short or contain sequences similar to others (e.g. different isoforms) might not be possible without 
cross-reactivity. Using many probes per target sequence might increase the size of the resulting spot. Having too many fluorophores in close proximity may also result in auto-quenching of the fluorophore (Wolfbeis, 2005). Increasing the number of fluorophores per probe also increases the costs. There are two approaches for indirect labeling: use of antibodies and the use of enzymes. Using a primary-secondary or even an added tertiary antibody will amplify the signal for each tier since multiple secondaries can bind to a single primary antibody (similar for tertiary antibodies to secondaries). Using enzymes will produce signal that diffuses within the cell. Both amplification approaches result in a larger spot and thereby decreasing the resolution. A balance between sensitivity and accuracy based on resolution needs to be chosen well.

\subsection{Technical limitations - AD}

\subsubsection{Limitations of the field}

A major issue in the field is that it is difficult to compare between studies. One factor is differences of sample acquisition. The protein levels in the CSF are dependent on the circadian rhythm. Therefore changes in the time of day when the lumbar puncture is performed may affect experimental results (Cicognola et al., 2015). Other artifacts may occur due to differences in processing of the CSF, i.e. speed of processing after lumbar puncture, centrifugation duration and properties, as well as the material of the equipment and containers used. Heterogeneity in the plastic composition of the equipment are known to absorb A $\beta$ and thereby may deplete the CSF of A $\beta$ for further analysis (Fourier et al., 2015). Furthermore, the way the samples are stored may also affect the protein composition of the CSF. Especially, thaw-freeze cycles are known to affect tau concentrations (Schoonenboom et al., 2005).

Another issue is the study cohort. Suitable controls need to be included (age, ethnicity, etc). However, obtaining CSF from subjects with no medical condition was not possible due to the local ethics commission. This would allow monitoring the disease onset, which is essential to develop therapies. Moreover, it is hard to find a study cohort that is in general representative of the (local) population.

The current diagnosis methods still relies on medical assessments, which have inaccuracies especially when dealing with early cases of AD. Since the development of the STED-based diagnosis depends on initial medical classification of the patients, the assay may not be able to reach full accuracy. This issue is illustrated by the fact that some patients were diagnosed 
differently in the course of the study, since accurate identification of similar dementia forms is difficult (Hulstaert et al., 1999). This interfered with the analysis and the development of a discriminator function. This can be countered by long-term studies. Further longitudinal follow-up studies are needed to confirm the results of this study and especially to test its prediction accuracy for $\mathrm{AD}$ at prodromal stages. Ideally, young adults would be followed until their death. CSF samples of those patients could be analyzed with respect to the patients' long-term medical history and autopsy data for more accurate diagnosis.

\subsection{Outlook}

The STED-based diagnosis method of AD and other aggregopathies might be remarkably improved by the development of new affinity probes. First, isoform- or conformation-specific affinity probes may refine the prediction accuracy by focusing on the toxic protein species only. Second, using smaller affinity probes like nanobodies or aptamers reduces the distance between the epitope and the fluorophore, therefore the spot size. This provides more precise information about the actual physical dimensions of the target, in this case $A \beta$ and tau particles. This might allow even the identification of the toxic species. Future generations of microscopes and novel microscopy techniques with improved resolution may further increase the precision.

Another factor that is often neglected is the influence of the dye on the staining results. The optophysical properties of the dye determine the image quality, like speed of bleaching or quantum yield. Quantum dots, for example, have a high quantum yield with low photobleaching. However, other factors need to be considered as well. Quantum dots are relatively large in size (5-50 nm; Massey et al., 2015). This would affect the diffusion properties of the affinity probe remarkably and thus impair tissue penetration, which is especially important when considering quantum dots for labeling of oligonucleotides for FISH. The size of the dye also affects the resolution of the image. The larger the dye, the larger the spot and thus the worse the resolution.

Another factor to keep in mind, is the dye's general physical property. Concerning this work, Atto647N, the dye that achieved the best results for this study, is highly hydrophobic (ZanettiDomingues et al., 2013). This may lead to unspecific binding, especially to membranes, and thus a suboptimal signal-to-noise ratio or even misleading artifacts. In extreme cases, it may cause the affinity probe to precipitate. 
Therefore, these factors should be taken into account when doing a staining since re-optimization may be required. Innovations in dye development may improve the staining and imaging results in general and due to the possibility of co-stainings/co-localizations and coincidence detection.

In conclusion, this work illustrates the need for optimization of even long established methods dependent on the imaging technique and sample type used. This allows the acquisition of detailed and therefore more accurate data. Both projects presented represent first steps in the fields of RNA and medical research encouraging follow-up or new studies and re-investigation of past questions, which were not able to be answered due to the lack of resolution of conventional fluorescence microscopy. 


\section{Material and methods}

All experiments were performed at room temperature unless otherwise stated.

\subsection{General chemicals and manufacturers}

The laboratory equipment and chemicals used in this work were purchased from the companies or were provided from groups of the institutions stated in the following table. For individual cases within the rest of the document, only the short company name will be given. Please refer to this table for more information.

(A) Table | List of manufacturers and institutes.

\begin{tabular}{|c|c|c|}
\hline company / institute & city, state & country \\
\hline Abcam & Cambridge & UK \\
\hline ATTO-TEC GmbH & Siegen & Germany \\
\hline Covance Inc. & Princeton, NJ & USA \\
\hline Chroma Technology Corp. & Bellow Falls, VT & USA \\
\hline Dako Cytomation & Glostrup & Denmark \\
\hline Eppendorf & Hamburg & Germany \\
\hline Eurofins Scientific GmbH & Hamburg & Germany \\
\hline GE Healthcare & Little Chalfont & UK \\
\hline Gerhard Menzel GmbH & Braunschweig & Germany \\
\hline Gibco & Paisley & UK \\
\hline Instituto de Salud Carlos III & Madrid & Spain \\
\hline Invitrogen & Carlsbad, CA & USA \\
\hline Leica Microsystems GmbH & Mannheim & Germany \\
\hline Life Technologies & Carlsbad, CA & USA \\
\hline Lonza GmbH & Cologne & Germany \\
\hline $\begin{array}{l}\text { Max-Planck-Institute for Biophysical } \\
\text { Chemistry }\end{array}$ & Göttingen & Germany \\
\hline $\begin{array}{l}\text { Max-Planck-Institute for } \\
\text { Experimental Medicine }\end{array}$ & Göttingen & Germany \\
\hline Merck Millipore & Darmstadt & Germany \\
\hline
\end{tabular}




\begin{tabular}{|l|l|l|}
\hline company / institute & city, state & country \\
\hline New England Biolabs & Frankfurt am Main & Germany \\
\hline Newport Spectra-Physics GmbH & Darmstadt & Germany \\
\hline Olympus Corporation & Tokyo & Japan \\
\hline PAA Laboratories GmbH & Clöbe & Germany \\
\hline Peptide Specialty Laboratory (PSL) & Heidelberg & Germany \\
\hline AJ Roboscreen GmbH & Jena & Germany \\
\hline Seqlab & Göttingen & Germany \\
\hline Sigma Aldrich & St. Louis, MO & USA \\
\hline Synaptic Systems & Göttingen & Germany \\
The Mathworks Inc. & Natick, MA & USA \\
\hline Universitätsklinkum Tübingen & Tübingen & Germany \\
\hline University Medical Center & Göttingen & Germany \\
\hline
\end{tabular}

\subsection{Buffers and solutions}

Phosphate-buffered saline (PBS): $137 \mathrm{mM} \mathrm{NaCl}, 2.7 \mathrm{mM} \mathrm{KCl}, 10 \mathrm{mM} \mathrm{Na} \mathrm{HPO}_{4}, 2 \mathrm{mM}$ $\mathrm{KH}_{2} \mathrm{PO}_{4} ; \mathrm{pH} 7.4$.

High salt PBS: 500 mM NaCl, 2.7 mM KCl, 10 mM Na2PO4, 2.0 mM KH2PO4; pH 7.4

Paraformaldehyde (PFA): 4\% PFA (Merck) in PBS. Preparation: 8 g PFA was dissolved in 180 $\mathrm{ml}$ de-ionized water by mixing at mild heating and addition of $200 \mu \mathrm{l} 10 \mathrm{M} \mathrm{NaOH}$. After adding 20 $\mathrm{ml}$ 10x PBS, $\mathrm{pH} 7.4$, the $\mathrm{pH}$ was adjusted to 7.4 with $\mathrm{HCl}$. The solution was aliquoted and stored at $-20^{\circ} \mathrm{C}$ until the day of the experiment.

Tris buffer: $1 \mathrm{M}$ tris, adjust to $\mathrm{pH} 8.0$ with $\mathrm{HCl}$.

Mowiol: 2.4 g Mowiol 4-88 (Merck), 6 g glycerol, $6 \mathrm{ml}$ de-ionized water and $12 \mathrm{ml} 0.2 \mathrm{M}$ Tris buffer. Preparation: The chemicals were mixed up to 5 days at mild heating and adjusted to $\mathrm{pH} 8.5$ with $\mathrm{HCl}$. The solution was aliquoted, flash-frozen, and stored at $-20^{\circ} \mathrm{C}$. 


\subsection{Antibodies}

(B) Table | List of antibodies.

\begin{tabular}{|c|c|c|c|}
\hline target & $\begin{array}{c}\text { company/ } \\
\text { institute }\end{array}$ & catalogue number / clone & host \\
\hline $\mathrm{A} \beta$ & Synaptic Systems & $\begin{array}{r}218511 \\
\\
\end{array}$ & $\begin{array}{l}\text { mouse } \\
\text { monoclonal }\end{array}$ \\
\hline $\mathrm{A} \beta$ & covance & $\begin{array}{r}\text { SIG-39300 } \\
\text { (6E10) }\end{array}$ & mouse \\
\hline $\mathrm{A} \beta$ & Bayer lab & 167 & mouse \\
\hline $\mathrm{A} \beta$ & Synaptic Systems & 218211 NT244 & mouse \\
\hline $\mathrm{A} \beta$ & Synaptic Systems & $\begin{array}{ll}218111 & \\
& \text { NT78 }\end{array}$ & $\begin{array}{l}\text { mouse } \\
\text { monoclonal }\end{array}$ \\
\hline $\mathrm{A} \beta$ & Synaptic Systems & $\begin{array}{ll}218311 & \\
& 157\end{array}$ & $\begin{array}{l}\text { mouse } \\
\text { monoclonal }\end{array}$ \\
\hline $\mathrm{A} \beta$ & Synaptic Systems & $218011 \quad 2$ & $\begin{array}{l}\text { mouse } \\
\text { monoclonal }\end{array}$ \\
\hline $\mathrm{A} \beta$ & Abcam & ab10148 & $\begin{array}{ll}\text { rabbit } & \\
& \text { polyclonal }\end{array}$ \\
\hline $\mathrm{A} \beta$ & Abcam & ab12267 & $\begin{array}{rr}\text { rabbit } & \\
& \text { polyclonal }\end{array}$ \\
\hline APP & Synaptic Systems & 127002 & rabbit \\
\hline tau & Dako Cytomation & A0024 & rabbit \\
\hline p-tau & Abcam & ab4856 & rabbit \\
\hline p-tau & Life Technologies & $\begin{array}{r}\text { MN1060 } \\
\text { AT100 }\end{array}$ & mouse \\
\hline p-tau & Life Technologies & $\begin{array}{l}\text { MN1020 } \\
\text { AT8 }\end{array}$ & mouse \\
\hline$\alpha$-synuclein & Invitrogen & $32-8100$ & mouse \\
\hline$\alpha$-synuclein & Abcam & ab27766 & mouse \\
\hline$\alpha$-synuclein & roboscreen & $\begin{array}{r}102004001 \\
5 \mathrm{G} 4\end{array}$ & $\begin{array}{l}\text { mouse } \\
\text { monoclonal }\end{array}$ \\
\hline$\alpha$-synuclein & roboscreen & $\begin{array}{r}102001801 \\
10 \mathrm{C} 3\end{array}$ & $\begin{array}{l}\text { mouse } \\
\text { monoclonal }\end{array}$ \\
\hline$\alpha$-synuclein & roboscreen & $\begin{array}{r}102004701 \\
10 \mathrm{D} 2\end{array}$ & $\begin{array}{l}\text { mouse } \\
\text { monoclonal }\end{array}$ \\
\hline$\alpha / \beta$-synuclein & Synaptic Systems & 128002 & rabbit \\
\hline synaptophysin & Synaptic Systems & 101004 & $\begin{array}{l}\text { guinea pig } \\
\text { polyclonal }\end{array}$ \\
\hline
\end{tabular}




\begin{tabular}{|c|c|c|l|}
\hline target & $\begin{array}{c}\text { company/ } \\
\text { institute }\end{array}$ & catalogue number / clone & \multicolumn{1}{c|}{ host } \\
\hline MAP2 & Abcam & ab11267 & $\begin{array}{l}\text { mouse } \\
\text { monoclonal }\end{array}$ \\
\hline A11 & Invitrogen & AHB0052 & rabbit polyclonal \\
\hline OC & Merck & AB2286 & rabbit polyclonal \\
\hline
\end{tabular}

\subsection{Coverslip preparation}

Thin coverslips ( $<100 \mu \mathrm{m}$, Gerhard Menzel) used for all experiments were acid-cleaned (1 M HCl overnight, then $1 \mathrm{M} \mathrm{NaOH}$ for 45 minutes). The coverslips were extensively washed with deionized water after each acid or base incubation. The coverslips were stored in 100\% EtOH until flaming prior to overnight coating with poly-L-lysine (PLL; $0.1 \mathrm{mg} / \mathrm{ml}$ ).

\subsection{Cell culture}

\subsubsection{PC12 cells}

PC12 cells - derived from pheochromocytoma of the rat adrenal medulla (Heumann et al., 1983) were cultured in standard Dulbecco's modified Eagle’s medium (DMEM, Lonza) enriched with 10\% horse serum (Merck), 5\% fetal calf serum (PAA), 4 mM L-glutamine (Sigma-Aldrich), and $100 \mathrm{U} / \mathrm{ml}$ each of penicillin and streptomycin (Lonza) at $37^{\circ} \mathrm{C}, 5 \% \mathrm{CO}_{2}, 90 \%$ humidity. Cells were seeded on PLL-coated coverslips of $18 \mathrm{~mm}$ diameter 24 hours prior to the experiment. For passaging, the cells were harvested by trypsin/EDTA (Lonza) treatment.

\subsubsection{COS-7 cells}

COS-7 cells - green monkey kidney fibroblast-like cells transformed by the simian virus 40 (SV40, Invitrogen) - were cultured in standard DMEM enriched with $10 \%$ fetal calf serum, $2 \mathrm{mM} \mathrm{L-}$ glutamine, and $100 \mathrm{U} / \mathrm{ml}$ each of penicillin and streptomycin at $37^{\circ} \mathrm{C}, 5 \% \mathrm{CO}_{2}, 90 \%$ humidity. 
Cells were seeded on PLL-coated coverslips of $18 \mathrm{~mm}$ diameter 24 hours prior to the experiment. For passaging, the cells were harvested by trypsin/EDTA treatment.

\subsubsection{Neuronal culture}

Primary hippocampal neurons of newborn rats were seeded on a previously grown astrocyte layer on PLL-coated coverslips of $18 \mathrm{~mm}$ diameter. The neurons were cultured in Neurobasal A (Invitrogen) enriched with 2\% B27 (Invitrogen), 1\% glutamax-I (Invitrogen), $60 \mathrm{U} / \mathrm{ml}$ penicillin, and $20 \mathrm{U} / \mathrm{ml}$ streptomycin at $37^{\circ} \mathrm{C}, 5 \% \mathrm{CO}_{2}, 90 \%$ humidity.

\subsection{Fluorescence in situ hybridization (FISH)}

\subsubsection{Probe design}

All DNA oligonucleotides were purchased from Eurofins. The probes were designed to have similar hybridization properties using a custom MatLab (The Mathworks Inc) macro to find all nonoverlapping sequences of 55 nucleotides with a GC content between $45.5 \%$ and $56.4 \%$. Those candidates were checked for possible cross-reactions by aligning their sequences against the rat mRNA database (RefSeq, NCBI database). All candidates with more than 25\% of their sequence reverse complementary to unspecific targets were removed. Sequences spanning contiguous exons were preferred to detect mature mRNAs specifically. The probes were labeled with one Atto647N fluorophore at each end. This increased the signal while avoiding self-quenching of the fluorophore and alteration of the hybridization properties. Three probes were chosen for each target resulting in, in theory, three probes with six fluorophores per target mRNA molecule. A list of the probes used can be viewed in the subsequent table (Table A).

(C) Table | List of FISH probes with their sequences and fluorophores.

\begin{tabular}{|l|l|}
\hline target mRNA (probe name) & probe sequence (all sequences from 5' to 3') \\
\hline$\beta$-actin (coding sequence; act\#1) & $\begin{array}{l}\text { TTC TCC ATA TCG TCC CAG TTG GTT ACA ATG CCG TGT } \\
\text { TCA ATG GGG TAC TTC AGG G }\end{array}$ \\
\hline$\beta$-actin (coding sequence; act\#2) & $\begin{array}{l}\text { AGG TCT CAA ACA TGA TCT GGG TCA TCT TTT CAC GGT } \\
\text { TGG CCT TAG GGT TCA GAG G }\end{array}$ \\
\hline$\beta$-actin (coding sequence; act\#3) & $\begin{array}{l}\text { ACC AGA CAG CAC TGT GTT GGC ATA GAG GTC TTT ACG } \\
\text { GAT GTC AAC GTC ACA CTT C }\end{array}$ \\
\hline
\end{tabular}




\begin{tabular}{|c|c|}
\hline target mRNA (probe name) & probe sequence (all sequences from 5' to 3') \\
\hline synaptophysin (coding sequence; syp\#1) & $\begin{array}{l}\text { TTG AAC ACG AAC CAT AAG TTG CCA ACC CAG AGC ACC } \\
\text { AGG TTC AGG AAG CCA AAC A }\end{array}$ \\
\hline synaptophysin (coding sequence; syp\#2) & $\begin{array}{l}\text { GTG TAG CTG CCA CAC GTA GCA AAG GCG AAG ATG GCA } \\
\text { AAG ACC CAC TGC AGC ACC T }\end{array}$ \\
\hline synaptophysin (coding sequence; syp\#3) & $\begin{array}{lllllll}\text { GCA } & \text { TCT } & \text { CCT } & \text { TGA } & \text { TAA } & \text { TGT } & \text { TCT } \\
\text { TCT } & \text { TCA } & \text { CAT } & \text { CGG ACA } & \text { GGC C }\end{array}$ \\
\hline synaptophysin (UTR; syp_utr\#1) & $\begin{array}{l}\text { AAC AGC AAA GAC AGT TAG GGT CTC CTG GGT TGA GGG } \\
\text { GTG GAG ACC TAG GAT ATG G }\end{array}$ \\
\hline synaptophysin (UTR; syp_utr\#2) & $\begin{array}{lllllllll}\text { TCC } & \text { TCT } & \text { CTC } & \text { TAC } & \text { AGA } & \text { GGT } & \text { TAT } & \text { CTC } & \text { CTC } \\
\text { TTC } & \text { ACC } & \text { CAA } & \text { GCC } & \text { TCC } & \text { TCC } & \text { A }\end{array}$ \\
\hline synaptophysin (UTR; syp_utr\#3) & $\begin{array}{l}\text { GAG CCC GCT GTG TTT AAG CCA CAC CCC TCC TAG AAC } \\
\text { CAC TCT CTC TGG TCA CTT A }\end{array}$ \\
\hline synaptotagmin (coding sequence; syt\#1) & $\begin{array}{l}\text { CAT AAA CTT CTG CTT CAG CTT GGA AAA GGC ATC TTC } \\
\text { CTT CCC TTC CCC AGG ACT G }\end{array}$ \\
\hline synaptotagmin (coding sequence; syt\#2) & $\begin{array}{l}\text { CTG GAG ATC ACG CCA CTC CTC GGT CAC ATG GCC AAA } \\
\text { ATC CAC GGT GTT CAT AGG A }\end{array}$ \\
\hline synaptotagmin (coding sequence; syt\#3) & $\begin{array}{l}\text { GCC CCA GTG CTG TTG TAA CCA ACG AAG ACT TTG CCG } \\
\text { ATG GCG TCG TTC TTG CCA A }\end{array}$ \\
\hline synaptotagmin (UTR; syt_utr\#1) & $\begin{array}{l}\text { CAA AGT CTT CCG ATC TGA CTG CGG ATG TTG GTT GCT } \\
\text { CAA GCG CTT TCA AGT CTT C }\end{array}$ \\
\hline synaptotagmin (UTR; syt_utr\#2) & $\begin{array}{l}\text { CTC GGA ATC TTT CTT CAA TCT TAA TGA GAC GTT CTG } \\
\text { GTG GCG CTC TGG GGA TGG C }\end{array}$ \\
\hline synaptotagmin (UTR; syt_utr\#3) & $\begin{array}{l}\text { ACA GAT ACT GGC TAA AGA GCA CTA TGT GGG CAG ATG } \\
\text { CAG AAA GGC TTC GTT TTC C }\end{array}$ \\
\hline synaptobrevin (coding sequence; syb\#1) & $\begin{array}{llllllll}\text { AGA TGA } & \text { TCA } & \text { TCA } & \text { TCT } & \text { TGA } & \text { GGT TTT TCC ACC AGT ATT } \\
\text { TGC GCT TGA } & \text { GCT TGG } & \text { CTG C }\end{array}$ \\
\hline synaptobrevin (coding sequence; syb\#2) & 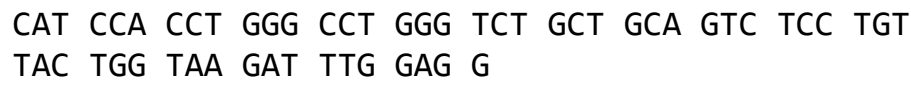 \\
\hline synaptobrevin (coding sequence; syb\#3) & $\begin{array}{l}\text { CGA TCA TCC AGT TCC GAT AGC TTC TGG TCC CGC TCC } \\
\text { AGG ACC TTG TCC ACA TTC A }\end{array}$ \\
\hline synaptobrevin (UTR; syb_utr\#1) & $\begin{array}{l}\text { TAA CAG CTG GCT ATT TAC AGG GGG CAC ACA CAC GGA } \\
\text { CAC ACA CAC ACA CGG ATC C }\end{array}$ \\
\hline synaptobrevin (UTR; syb_utr\#2) & $\begin{array}{l}\text { GGG GTT TGC TCT GTT TGG GGA GGG TCT GGA ATT GTA } \\
\text { CAG GGA AGA TAG GGG AAG G }\end{array}$ \\
\hline synaptobrevin (UTR; syb_utr\#3) & $\begin{array}{l}\text { GAG GCT CCC AAG GGA TAC AAA GAT GCA ACC TAT GGA } \\
\text { AGC CTA GAC AGG TGG GGT G }\end{array}$ \\
\hline random control probes (rnd\#1) & $\begin{array}{l}\text { TTA AAC ACA ACG ACG ACC GGG AAC AAT CAT TAT GGC } \\
\text { ACG CGG AGC AAT GGC TAA C }\end{array}$ \\
\hline random control probes (rnd\#2) & $\begin{array}{l}\text { AGA CGC AAC AAG ATT ACG TAC GCG AAC GAA GTA CGC } \\
\text { ACG TCA GGT TCA AAT CGC A }\end{array}$ \\
\hline random control probes (rnd\#3) & $\begin{array}{l}\text { GAC CTA ATA CGT ACC ACC CGA AGG GTA CGT GTA AAG } \\
\text { ATA GGC CGA CTA CGA AAC A }\end{array}$ \\
\hline
\end{tabular}




\subsubsection{Immunostaining of cells (after FISH)}

After the last rinse with $1 \mathrm{x}$ SSC during the FISH procedure, the cells were fixed with 4\% paraformaldehyde (PFA) and quenched again, as described previously. The cells were then permeabilized with $0.1 \%$ Triton-X (Merck) in PBS for 5 minutes. Primary and secondary antibodies were diluted 1:250 and 1:1000, respectively, in 1.5\% bovine serum albumin (BSA) and 0.1\% Triton-X in PBS. Guinea pig anti-synaptophysin and mouse anti-MAP2 antibodies were incubated prior to fluorescently labeled secondary antibodies. Each antibody incubation of 1 hour was followed by extensive washings with PBS. The cells were then embedded in Mowiol and stored as described above.

\subsection{Immunostaining of CSF}

\subsubsection{Synthetic $A \beta$ samples}

$\mathrm{A} \beta_{4-38}$ and $A \beta_{1-42}$ peptides were dissolved in 1,1,1,3,3,3-hexafluoro-2-propanol (HFIP, PSL), flashfrozen in liquid nitrogen, and then lyophilized to completely remove the solvent. Lyophilized $A \beta$ peptides were re-dissolved in $100 \mathrm{mM} \mathrm{NaOH}$ at a concentration of $2 \mathrm{mg} / \mathrm{ml}$, aliquoted, flash-frozen with liquid nitrogen, and stored at $-80^{\circ} \mathrm{C}$ until use. Size-exclusion chromatography (SEC) was performed using a Superose 6 10/300 column (GE Healthcare) connected to an ÄKTApurifier ${ }^{\mathrm{TM}} 10$ UPC 900 system (GE Healthcare). The samples were prepared in phosphate buffer (50 mM, pH 7.4) with $50 \mathrm{mM} \mathrm{NaCl}$, at a peptide concentration of $0.5 \mathrm{mg} / \mu \mathrm{l}$ and then incubated at $37^{\circ} \mathrm{C}$ for $24 \mathrm{~h}$, without further promotion of aggregation by agitation. After a short centrifugation step, $250 \mu \mathrm{l}$ of peptide solution was loaded onto the column at a flow rate of $0.5 \mathrm{ml} / \mathrm{min}$. The peptide elution was monitored by UV absorbance at 215 and $265 \mathrm{~nm}$. The SEC peaks were calibrated and corresponding stoichiometries were calculated as previously published (Paivio et al., 2004). A $\beta_{4-38}$ was used to isolate stable LMW (dimers/trimers) and $A \beta_{1-42}$ for HMW aggregates (Bouter et al., 2013). 


\subsubsection{Human subjects}

Cerebrospinal fluid (CSF) was collected and stored at one clinical center according to one standard operation procedure (SOP) to minimize storage and sample handling artifacts. CSF was obtained from the Biobank at the Department of Psychiatry (University Medical Center). Patients with Alzheimer's Disease (AD) and mild cognitive impairment (MCI) were clinically phenotyped by neuropsychological testing (CERAD Plus test battery as the minimum assessment), neurological examination, MRI, and CSF diagnostics by the Memory Clinic's specialized physicians (University Medical Center). AD diagnosis was based on the criteria of the National Institute of Neurological and Communicative Disorders and Stroke and the Alzheimer's Disease and Related Disorders Association (NINCDS-ADRDA). Patients with preserved activities of daily living but showing a combination of memory complaints plus a performance of 1-1.5 standard deviations below the age norm on at least one cognitive domain of the CERAD Plus test battery were considered as MCIs (Winblad et al., 2004). Control samples were provided by the Departments of Psychiatry and Neurology (University Medical Center) including patients with schizophrenia, bipolar disorder, depression, multiple sclerosis, and headache. Patients of the control group with memory deficits (e.g. due to negative symptoms caused by schizophrenia) were neuropsychologically assessed and patients with dementia or neurodegenerative diseases were excluded from controls. Biosampling was conducted according to the Declaration of Helsinki and was approved by the ethics committee of the University Medical Center Göttingen (approval number 2/5/09) and all patients gave informed written consent. For detailed information, please refer to Tables B-E.

\subsubsection{CSF samples}

CSF samples were collected at the memory clinic and the Department of Psychiatry (University Medical Center) starting in 2010, following identical SOPs. In short, CSF was obtained between 9 a.m. and 1 p.m. and centrifuged for 10 minutes at 2000x g and room temperature within 20 minutes after the lumbar puncture. The supernatant was then aliquoted, flash frozen, and stored at $-80^{\circ} \mathrm{C}$. CSF samples containing blood contamination were excluded.

Six post-mortem CSF samples from confirmed AD patients were obtained from the Tissue Bank, Fundación CIEN (Instituto de Salud Carlos III). Rapid brain autopsies were performed according to the brain bank protocol (Martinez-Martin et al., 2010). CSF (10-15 ml on average) was obtained during autopsy by puncture of the III $^{\text {rd }}$ ventricle through its floor, immediately behind the optic chiasm before removal of the brain. The CSF was assessed regarding to its color and macroscopic 
properties, as well as its $\mathrm{pH}$ was measured. The CSF samples were subsequently centrifuged for 8 minutes at $1300 \mathrm{x} \mathrm{g}$ and $4^{\circ} \mathrm{C} .0 .5-1 \mathrm{ml}$ aliquots of the supernatant were prepared and stored as stated above.

Enzyme-linked immunosorbent assay (ELISA) measurements of these samples were performed commercially (Universitätsklinikum Tübingen) according established methods. The quantities of $\mathrm{A} \beta_{1-42}$ and tau were determined and are shown in Tables B-E.

(D) Table | Patient information and CSF properties from controls.

\begin{tabular}{|c|c|c|c|c|c|c|}
\hline ID & diagnosis & sex & $\begin{array}{c}\text { age } \\
\text { [years] }\end{array}$ & $\begin{array}{c}\text { Abeta } \\
\text { [pg/ml] }\end{array}$ & $\begin{array}{c}\text { tau } \\
\text { [pg/ml] }\end{array}$ & $\mathbf{F}_{\mathrm{A} \beta}$ \\
\hline 63 & fragile $X$ & $\mathrm{~m}$ & 20 & 576 & 91 & 45.616 \\
\hline 67 & polyneuropathy & $\mathrm{f}$ & 64 & 669 & 175 & 3.794 \\
\hline 78 & multiple sclerosis & $\mathrm{f}$ & 60 & 240 & 979 & 56.714 \\
\hline 92 & schizophrenia & $\mathrm{m}$ & 59 & 440 & 197 & 63.227 \\
\hline 101 & schizophrenia & $\mathrm{m}$ & 49 & 469 & 190 & 3.594 \\
\hline 106 & multiple sclerosis & $\mathrm{m}$ & 57 & 781 & 290 & 37.753 \\
\hline 120 & severe depression & $\mathrm{f}$ & 57 & 622 & 347 & 55.442 \\
\hline 126 & schizophrenia & $\mathrm{m}$ & 42 & 1265 & 365 & 54.643 \\
\hline 130 & schizophrenia & $\mathrm{m}$ & 19 & 790 & 202 & 47.392 \\
\hline 131 & severe depression & $\mathrm{m}$ & 60 & 632 & 339 & 35.724 \\
\hline 132 & schizophrenia & $\mathrm{f}$ & 34 & 518 & 154 & 5.028 \\
\hline 135 & severe depression & $\mathrm{m}$ & 48 & 809 & 217 & 27.836 \\
\hline 138 & $\begin{array}{l}\text { anxiety, } \\
\text { depression }\end{array}$ & $\mathrm{f}$ & 48 & 621 & 214 & 42.764 \\
\hline 140 & depression & $\mathrm{f}$ & 63 & 828 & 613 & 40.098 \\
\hline 151 & schizophrenia & $\mathrm{f}$ & 42 & 654 & 150 & 35.071 \\
\hline 161 & severe depression & $\mathrm{f}$ & 24 & 182 & 788 & 49.997 \\
\hline 166 & severe depression & $\mathrm{m}$ & 48 & 452 & 97 & 41.773 \\
\hline 167 & schizophrenia & $\mathrm{m}$ & 20 & 690 & 136 & 46.549 \\
\hline 172 & schizophrenia & $\mathrm{f}$ & 55 & 915 & 226 & 50.501 \\
\hline 173 & schizophrenia & $\mathrm{m}$ & 23 & 914 & 287 & 48.022 \\
\hline 177 & severe depression & $\mathrm{m}$ & 54 & 1006 & 296 & 44.856 \\
\hline
\end{tabular}

(E) Table | Patient information and CSF properties from AD patients.

\begin{tabular}{|c|c|c|c|c|c|c|c|}
\hline ID & sex & $\begin{array}{c}\text { age } \\
\text { [years] }\end{array}$ & MMSE & $\begin{array}{c}\text { Abeta } \\
{[\mathrm{pg} / \mathrm{ml}]}\end{array}$ & $\begin{array}{c}\text { tau } \\
{[\mathrm{pg} / \mathrm{ml}]}\end{array}$ & $F_{A \beta}$ & $F_{A \beta, \text { tau }}$ \\
\hline 4 & $\mathrm{~m}$ & 70 & 23 & 423 & 136 & 2.747 & 12.933 \\
\hline 6 & $f$ & 69 & 9 & 275 & 927 & 2.585 & 12.576 \\
\hline 16 & $\mathrm{~m}$ & 79 & 26 & 170 & 424 & 36.484 & 16.928 \\
\hline 22 & m & 58 & 17 & 613 & 109 & 29.683 & 14.698 \\
\hline 47 & $\mathrm{~m}$ & 64 & 27 & 334 & 422 & 42.355 & 16.676 \\
\hline 57 & m & 73 & 22 & 269 & 253 & 15.997 & 0.9657 \\
\hline
\end{tabular}




\begin{tabular}{|cccccccc|}
\hline 60 & $\mathrm{f}$ & 78 & 21 & 223 & 346 & 37.072 & 14.241 \\
\hline 61 & $\mathrm{f}$ & 59 & 17 & 229 & 832 & 16.045 & 10.675 \\
\hline 65 & $\mathrm{f}$ & 83 & 6 & 260 & 342 & 12.268 & 0.9709 \\
\hline 69 & $\mathrm{~m}$ & 72 & 22 & 215 & 477 & 10.848 & 0.8931 \\
\hline 73 & $\mathrm{~m}$ & 74 & 22 & 220 & 368 & 30.845 & 16.877 \\
\hline 76 & $\mathrm{~m}$ & 63 & 25 & 311 & 425 & 28.863 & 15.778 \\
\hline 84 & $\mathrm{f}$ & 74 & 27 & 285 & 327 & 30.735 & 11.852 \\
\hline 89 & $\mathrm{f}$ & 54 & 20 & 135 & 725 & 11.943 & \\
\hline 98 & $\mathrm{f}$ & 76 & 24 & 489 & 422 & 37.647 & 16.408 \\
\hline 107 & $\mathrm{f}$ & 78 & 22 & 224 & 542 & 37.069 & 16.408 \\
\hline 111 & $\mathrm{~m}$ & 62 & 27 & 316 & 828 & 33.758 & 15.455 \\
\hline 112 & $\mathrm{f}$ & 72 & 25 & 12 & 140 & 49.645 & 19.203 \\
\hline 114 & $\mathrm{f}$ & 69 & 26 & 439 & 323 & 31.976 & 16.496 \\
\hline 115 & $\mathrm{~m}$ & 71 & 28 & 307 & 424 & 24.652 & 22.336 \\
\hline 116 & $\mathrm{f}$ & 82 & 23 & 402 & 173 & 28.853 & \\
\hline 119 & $\mathrm{f}$ & 71 & 22 & 130 & 923 & 29.686 & 15.421 \\
\hline 123 & $\mathrm{f}$ & 75 & 23 & 443 & 832 & 46.084 & 14.502 \\
\hline 124 & $\mathrm{f}$ & 72 & 23 & 155 & 1033 & 46.037 & 13.553 \\
\hline 141 & $\mathrm{f}$ & 57 & 28 & 638 & 616 & 15.024 & \\
\hline 144 & $\mathrm{~m}$ & 73 & 27 & 368 & 652 & 48.801 & \\
\hline 145 & $\mathrm{~m}$ & 79 & 28 & 917 & 374 & 48.196 & \\
\hline 148 & $\mathrm{f}$ & 75 & 27 & 153 & 272 & 21.772 & \\
\hline 159 & $\mathrm{~m}$ & 67 & 21 & 567 & 152 & 51.414 & \\
\hline 163 & $\mathrm{~m}$ & 77 & 25 & 396 & 236 & 50.351 & \\
\hline & & & & & & & \\
\hline
\end{tabular}

(F) Table | Patient information and CSF properties from AD cases confirmed by autopsy.

\begin{tabular}{|c|c|c|c|c|}
\hline ID & sex & $\begin{array}{c}\text { age } \\
\text { [years] }\end{array}$ & $F_{A \beta}$ & $F_{A \beta, \text { tau }}$ \\
\hline 48 & $f$ & 84 & 0.9168 & 0.8542 \\
\hline 190 & $\mathrm{~m}$ & 94 & 0.6843 & 22.187 \\
\hline 213 & f & 91 & 1.582 & 14.741 \\
\hline 1742 & $f$ & 82 & 12.355 & 15.842 \\
\hline 1749 & $f$ & 67 & 16.383 & 1.258 \\
\hline 1752 & $\mathrm{~m}$ & 65 & 12.832 & 20.438 \\
\hline
\end{tabular}


(G) Table | Patient information and CSF properties from mild cognitive impaired (MCI). The asterisks indicate the patients that were diagnosed with full AD during the study.

\begin{tabular}{|c|c|c|c|c|c|c|c|}
\hline ID & sex & $\begin{array}{c}\text { age } \\
\text { [years] }\end{array}$ & MMSE & $\begin{array}{l}\text { Abeta } \\
\text { [pg/ml] }\end{array}$ & $\begin{array}{l}\text { tau } \\
\text { [pg/ml] }\end{array}$ & $F_{A \beta}$ & $F_{A \beta, \text { tau }}$ \\
\hline $59 *$ & $f$ & 78 & 29 & 160 & 410 & 29.371 & 12.855 \\
\hline 72 & $\mathrm{~m}$ & 65 & 28 & 327 & 617 & 24.176 & 12.979 \\
\hline 74 & $\mathrm{~m}$ & 70 & 27 & 254 & 286 & 29.023 & 1.448 \\
\hline 80 & $\mathrm{~m}$ & 54 & 26 & & & 23.497 & 11.403 \\
\hline 81 & $\mathrm{~m}$ & 71 & 25 & 336 & 1147 & 1.349 & 0.9682 \\
\hline 83 & $\mathrm{~m}$ & 70 & 27 & 474 & 188 & 64.559 & 23.248 \\
\hline 86 & $\mathrm{~m}$ & 59 & 30 & 286 & 178 & 58.355 & 21.622 \\
\hline 91 & $\mathrm{~m}$ & 71 & 30 & 561 & 327 & 49.994 & 17.832 \\
\hline 94 & $f$ & 67 & 28 & 837 & 150 & 36.526 & 14.384 \\
\hline $95^{\star}$ & $f$ & 74 & 28 & 235 & & 45.476 & 15.715 \\
\hline 164 & $\mathrm{~m}$ & 64 & 29 & 881 & 424 & 45.028 & \\
\hline
\end{tabular}

\subsubsection{Immunostaining}

Freshly prepared PLL-coated coverslips were briefly washed with PBS and CSF samples were immediately added for 30 minutes in a humidifying chamber. The CSF was then fixed with $4 \%$ PFA for 25 minutes and quenched with $0.1 \mathrm{M} \mathrm{NH}_{4} \mathrm{Cl}$ for 10 minutes. Unless otherwise stated, the samples were blocked for 30 minutes with 5\% BSA and 5\% peptone in PBS. The CSF was immunostained with the respective primary antibody in blocking solution for one hour. Excess antibodies were removed by three washings with PBS for 5 minutes each before 1 hour incubation with secondary Fab fragments coupled to Atto647N fluorophores in blocking solution. The coverslips were subsequently rinsed three times with high salt PBS and twice with PBS for 5 minutes each. The coverslips were embedded and stores as described above.

\subsection{Epifluorescence imaging}

Wide-field fluorescence images were taken at an Olympus IX71 microscope (Olympus) equipped with an 100x oil TIRFM objective (1.45 numerical aperture, NA; Olympus) and an F-View II charge-coupled device (CCD) camera (1376 pixels x 1032 pixels with a pixel size of $6.45 \mu \mathrm{m}$ x $6.45 \mu \mathrm{m})$. All filters were purchased from Chroma and are listed in Table $\mathrm{H}$. 
(H) Table | List of filter cubes for epifluorescence imaging.

\begin{tabular}{|c|c|c|c|}
\hline filter & excitation & beamsplitter & emission \\
\hline DAPI & $350 / 50 \mathrm{D}$ & $400 \mathrm{DCLP}$ & $460 / 50 \mathrm{D}$ \\
\hline FITC & $480 / 40 \mathrm{HQ}$ & $505 \mathrm{LP} \mathrm{Q}$ & $527 / 30 \mathrm{HQ}$ \\
\hline TRITC & $545 / 30 \mathrm{HQ}$ & $570 \mathrm{LP} \mathrm{Q}$ & $610 / 75 \mathrm{HQ}$ \\
\hline Cy5 & $620 / 60 \mathrm{HQ}$ & $660 \mathrm{LP} \mathrm{Q}$ & $700 / 75 \mathrm{HQ}$ \\
\hline
\end{tabular}

\subsection{Confocal and STED imaging}

Confocal and STED images were taken at a Leica TCS SP5 STED microscope (Leica) with a 100x HCX PL APO CS oil objective (1.4 NA; Leica). A 635 nm pulsed diode laser (Leica) was used for excitation. To create the super-imposed donut for depletion, a Spectra-Physics MaiTai multiphoton laser at $750 \mathrm{~nm}$ (pulsed at $80 \mathrm{MHz}, \sim 1.3 \mathrm{~W}$ output power with the 100x objective, Titanium Sapphire; Newport Spectra-Physics) was used. For multichannel confocal imaging, the following settings were used: Argon laser at 488 nm for GFP, Cy2, or autofluorescence; Helium-Neon lasers at $594 \mathrm{~nm}$ or $633 \mathrm{~nm}$ for Cy3 or Atto647N, respectively. Images were taken sequentially line by line at a scanning frequency of $1000 \mathrm{~Hz}$ with 16 or 32 times for confocal and 96 times line averaging for STED mode. Fluorescence was detected by photomultiplier tubes (PMT) for confocal or by an avalanche photodiode (APD) for STED images using laser intensities with the best signalto-noise ratio for each experiment. The STED resolution $\sim 50 \mathrm{~nm}$.

\subsection{Image analysis}

All analyses were performed using custom-written macros (mostly developed by Silvio O. Rizzoli) for MatLab (Mathworks). For better visibility, STED images were deconvolved with Huygens Essential 3.3 (Scientific Volume Imaging) using a classical maximum likelihood estimation (CMLE) algorithm.

\subsection{Statistics}

All data is presented as mean \pm SEM, unless stated otherwise. SigmaPlot (Mathworks) was used for student's t-test (unpaired) and the p-values were obtained. Statistical significance is denoted as non- 
significant (n.s.) when $\mathrm{p}>0.05$; as $*$ when $\mathrm{P}<0.05$; as $* *$ when $\mathrm{p}<0.01$, and as $* * *$, when $\mathrm{P}<$ 0.001 . 


\section{Bibliography}

(2005) Springer Series on Fluorescence: Springer.

Abbe E (1873) Beiträge zur Theorie des Mikroskops und der mikroskopischen Wahrnehmung. Archiv f mikrosk Anatomie 9:413-418.

Alberts BJ, Alexander; Lewis, Julian; Raff, Martin; Roberts, Keith; Walter, Peter (2014) Molecular Biology of the Cell. New York: Garland Science.

Alzheimer A (1907) Über eine eigenartige Erkrankung der Hirnrinde. Allgemine Zeitschrift für Psychiatrie und physisch-gerichtliche Medizin 146-148.

Andreasen N, Blennow K (2005) CSF biomarkers for mild cognitive impairment and early Alzheimer's disease. Clinical neurology and neurosurgery 107:165-173.

Baker HvL, Anton (1739) An Account of Mr. Leeuwenhoek's Microscopes; by Mr. Henry Baker, F.R.S. Phil Trans 503-519.

Bartel D (2004) MicroRNA: genomics, biogenesis, mechanism, and function. Cell 116:281-297.

Betzig EP, GH; Sougrat, R; Lindwasser, OW; Olenych, S; Bonifacino, JS; Davidson, MW; Lippincott-Schwartz, J; Hess, HF (2006) Imaging intracellular fluorescent proteins at nanometer resolution. Science 1642-1645.

Blessed GT, BE; Roth, Martin (1968) The association between quantitative measures of dementia and of senile change in the cerebral gray matter of elderly subjects. Brit J Psychiatry 797811.

Bouter Y, Dietrich K, Wittnam JL, Rezaei-Ghaleh N, Pillot T, Papot-Couturier S, Lefebvre T, Sprenger F, Wirths O, Zweckstetter M, Bayer TA (2013) N-truncated amyloid beta (Abeta) 4-42 forms stable aggregates and induces acute and long-lasting behavioral deficits. Acta neuropathologica 126:189-205.

Cicognola C, Chiasserini D, Parnetti L (2015) Preanalytical Confounding Factors in the Analysis of Cerebrospinal Fluid Biomarkers for Alzheimer's Disease: The Issue of Diurnal Variation. Front Neurol 6:143.

Dickson DK-R, H; Liu, WK; Davies, P; Crowe, A; Yen, SH (1992) Immunocytochemistry of neurofibrillary tangles with antibodies to subregions of tau protein: identification of hidden and cleaved tau epitopes and a new phosphorylation site. Acta neuropathologica 84:596605.

Duce JA, Tsatsanis A, Cater MA, James SA, Robb E, Wikhe K, Leong SL, Perez K, Johanssen T, Greenough MA, Cho HH, Galatis D, Moir RD, Masters CL, McLean C, Tanzi RE, Cappai R, Barnham KJ, Ciccotosto GD, Rogers JT, Bush AI (2010) Iron-export ferroxidase activity of beta-amyloid precursor protein is inhibited by zinc in Alzheimer's disease. Cell 142:857867. 
Ebbesen KK, Kjems J, Hansen TB (2015) Circular RNAs: Identification, biogenesis and function. Biochim Biophys Acta.

Einstein A (1916) Strahlungs-Emission und -Absorption nach der Quantentheorie. Deutsche Physikalische Gesellschaft, Verhandlungen 318-323.

Erni RR, MD; Kisielowski, C; Dahmen, U (2009) Atomic-resolution imaging with a sub-50-pm electron probe. Phys Rev Lett 102.

Esparza TJ, Zhao H, Cirrito JR, Cairns NJ, Bateman RJ, Holtzman DM, Brody DL (2013) Amyloid-beta oligomerization in Alzheimer dementia versus high-pathology controls. Annals of neurology 73:104-119.

Fourier A, Portelius E, Zetterberg H, Blennow K, Quadrio I, Perret-Liaudet A (2015) Pre-analytical and analytical factors influencing Alzheimer's disease cerebrospinal fluid biomarker variability. Clin Chim Acta 449:9-15.

Fukumoto H, Tokuda T, Kasai T, Ishigami N, Hidaka H, Kondo M, Allsop D, Nakagawa M (2010) High-molecular-weight beta-amyloid oligomers are elevated in cerebrospinal fluid of Alzheimer patients. FASEB J 24:2716-2726.

Georganopoulou DG, Chang L, Nam JM, Thaxton CS, Mufson EJ, Klein WL, Mirkin CA (2005) Nanoparticle-based detection in cerebral spinal fluid of a soluble pathogenic biomarker for Alzheimer's disease. Proceedings of the National Academy of Sciences of the United States of America 102:2273-2276.

Glenner GG, Wong CW (1984) Alzheimer's disease: initial report of the purification and characterization of a novel cerebrovascular amyloid protein. Biochemical and biophysical research communications 425:534-539.

Golgi C (1873) Sulla struttura della sostanza grigia del cervello. Gazz Med Ital Lomb 244-246.

Heumann R, Kachel V, Thoenen H (1983) Relationship between NGF-mediated volume increase and "priming effect" in fast and slow reacting clones of PC12 pheochromocytoma cells. Role of cAMP. Experimental cell research 145:179-190.

Hoagland MK, EB; Zamecnik, PC (1956) Enzymatic carboxyl activation of amino acids. The Journal of biological chemistry 218:345-358.

Hooke R (1665) Micrographia: or some physiological descriptions of minute bodies made by magnifying glasses: with observations and iquiries thereupon. Courier Corporation.

Hulstaert F, Blennow K, Ivanoiu A, Schoonderwaldt HC, Riemenschneider M, Deyn PPD, Bancher C, Cras P, Wiltfang J, Mehta PD, Iqbal K, Pottel H, Vanmechelen E, Vanderstichele H (1999) Improved discrimination of AD patients using -amyloid(1-42) and tau levels in CSF. Neurology 52:1555-1555.

Irizarry M (2004) Biomarkers of Alzheimer disease in plasma. NeuroRx 1:226-234.

Jacob FM, Jacques (1961) Genetic Regulatory Mechanisms in the Synthesis of Proteins. Journal of molecular biology 318-356.

Kapranov P, Cheng J, Dike S, Nix DA, Duttagupta R, Willingham AT, Stadler PF, Hertel J, Hackermuller J, Hofacker IL, Bell I, Cheung E, Drenkow J, Dumais E, Patel S, Helt G, 
Ganesh M, Ghosh S, Piccolboni A, Sementchenko V, Tammana H, Gingeras TR (2007) RNA maps reveal new RNA classes and a possible function for pervasive transcription. Science 316:1484-1488.

Kayed R, Head E, Sarsoza F, Saing T, Cotman CW, Necula M, Margol L, Wu J, Breydo L, Thompson JL, Rasool S, Gurlo T, Butler P, Glabe CG (2007) Fibril specific, conformation dependent antibodies recognize a generic epitope common to amyloid fibrils and fibrillar oligomers that is absent in prefibrillar oligomers. Molecular neurodegeneration 2:18.

Lewis MA, Steel KP (2010) MicroRNAs in mouse development and disease. Semin Cell Dev Biol 21:774-780.

Maddalena AS, Papassotiropoulos A, Gonzalez-Agosti C, Signorell A, Hegi T, Pasch T, Nitsch RM, Hock C (2004) Cerebrospinal fluid profile of amyloid beta peptides in patients with Alzheimer's disease determined by protein biochip technology. Neurodegener Dis 1:231235.

Martinez-Martin P, Avila J, Investigators ADRU (2010) Alzheimer Center Reina Sofia Foundation: fighting the disease and providing overall solutions. Journal of Alzheimer's disease : JAD 21:337-348.

Massey M, Wu M, Conroy EM, Algar WR (2015) Mind your P's and Q's: the coming of age of semiconducting polymer dots and semiconductor quantum dots in biological applications. Curr Opin Biotechnol 34:30-40.

Mayeux R, Honig LS, Tang MX, Manly J, Stern Y, Schupf N, Mehta PD (2003) Plasma A 40 and A 42 and Alzheimer's disease: Relation to age, mortality, and risk. Neurology 61:11851190.

McKhann GM, Knopman DS, Chertkow H, Hyman BT, Jack CR, Jr., Kawas CH, Klunk WE, Koroshetz WJ, Manly JJ, Mayeux R, Mohs RC, Morris JC, Rossor MN, Scheltens P, Carrillo MC, Thies B, Weintraub S, Phelps CH (2011) The diagnosis of dementia due to Alzheimer's disease: recommendations from the National Institute on Aging-Alzheimer's Association workgroups on diagnostic guidelines for Alzheimer's disease. Alzheimer's \& dementia : the journal of the Alzheimer's Association 7:263-269.

Moerner WE (2006) Single-molecule mountains yield nanoscale cell images. Nature methods 3:781-782.

Morris M, Maeda S, Vossel K, Mucke L (2011) The many faces of tau. Neuron 70:410-426.

Motter RV-P, C; Kholodenko, D; Barbour, R; Johnson-Wood, K; Galasko, D; Chang, L; Miller, B; Clark, C; Green, R; Olson, D; Southwick, P; Wolfert, R; Munroe, B; Liebergurg, I; Seubert, P; Schenk, D (1995) Reduction of beta-amyloid peptide42 in the cerebrospinal fluid of patients with Alzheimer's disease. Annals of neurology 38:643-648.

Paivio A, Jarvet J, Graslund A, Lannfelt L, Westlind-Danielsson A (2004) Unique physicochemical profile of beta-amyloid peptide variant Abeta1-40E22G protofibrils: conceivable neuropathogen in arctic mutant carriers. Journal of molecular biology 339:145-159.

Pirttilä T, Kim K, Mehta PD, Frey H, Wisniewski H (1994) Soluble amyloid beta-protein in the cerebrospinal fluid from patients with Alzheimer's disease, vascular dementia and controls. J Neurol Sci 127:90-95. 
Priller C, Bauer T, Mitteregger G, Krebs B, Kretzschmar HA, Herms J (2006) Synapse formation and function is modulated by the amyloid precursor protein. The Journal of neuroscience : the official journal of the Society for Neuroscience 26:7212-7221.

Ramón y Cajal S (1917) Recuerdos de mi vida. Madrid: Moya.

Savage MJ, Kalinina J, Wolfe A, Tugusheva K, Korn R, Cash-Mason T, Maxwell JW, Hatcher NG, Haugabook SJ, Wu G, Howell BJ, Renger JJ, Shughrue PJ, McCampbell A (2014) A sensitive abeta oligomer assay discriminates Alzheimer's and aged control cerebrospinal fluid. The Journal of neuroscience : the official journal of the Society for Neuroscience 34:2884-2897.

Scheuner D, Eckman C, Jensen M, Song X, Citron M, Suzuki N, Bird T, Hardy J, Hutton M, Kukull W, Larson E, Levy-Lahad E, Viitanen M, Peskind E, Poorkaj P, Schellenberg G, Tanzi R, Wasco W, Lannfelt L, Selkoe D, Younkin S (1996) Secreted amyloid beta-protein similar to that in the senile plaques of Alzheimer's disease is increased in vivo by the presenilin 1 and 2 and APP mutations linked to familial Alzheimer's disease. Nat Med 2:864-870.

Schoonenboom NS, Mulder C, Vanderstichele H, Van Elk EJ, Kok A, Van Kamp GJ, Scheltens P, Blankenstein MA (2005) Effects of processing and storage conditions on amyloid beta (142) and tau concentrations in cerebrospinal fluid: implications for use in clinical practice. Clin Chem 51:189-195.

Shtengel G, Wang Y, Zhang Z, Goh WI, Hess HF, Kanchanawong P (2014) Imaging cellular ultrastructure by PALM, iPALM, and correlative iPALM-EM. Methods Cell Biol 123:273294.

Tapia JC, Kasthuri N, Hayworth KJ, Schalek R, Lichtman JW, Smith SJ, Buchanan J (2012) Highcontrast en bloc staining of neuronal tissue for field emission scanning electron microscopy. Nature protocols 7:193-206.

Terry RD, Masliah E, Salmon DP, Butters N, DeTeresa R, Hill R, Hansen LA, Katzman R (1991) Physical basis of cognitive alterations in Alzheimerr's disease: synapse loss is the major correlate of cognitive impairment. Annals of neurology 30:572-580.

Toomre D, Bewersdorf J (2010) A new wave of cellular imaging. Annual review of cell and developmental biology 26:285-314.

Turner PR, O’Connor K, Tate WP, Abraham WC (2003) Roles of amyloid precursor protein and its fragments in regulating neural activity, plasticity and memory. Progress in Neurobiology 70:1-32.

van Oijen M, Hofman A, Soares HD, Koudstaal PJ, Breteler MMB (2006) Plasma A $\beta 1-40$ and A $\beta 1-42$ and the risk of dementia: a prospective case-cohort study. The Lancet Neurology 5:655-660.

Viola KL, Klein WL (2015) Amyloid beta oligomers in Alzheimer's disease pathogenesis, treatment, and diagnosis. Acta neuropathologica 129:183-206.

Willig KI, Rizzoli SO, Westphal V, Jahn R, Hell SW (2006) STED microscopy reveals that synaptotagmin remains clustered after synaptic vesicle exocytosis. Nature 440:935-939.

Winblad B, Palmer K, Kivipelto M, Jelic V, Fratiglioni L, Wahlund L-O, Nordberg A, Bäckman L, Albert M, Almkvist O, Arai H, Basun H, Blennow K, de Leon M, Decarli C, Erkinjuntti T, 
van Duijn C, Visser P, Petersen RC (2004) Mild cognitive impariment - beyond controversies, towards a consensus: report of the International Working Group on Mild Cognitive Impairment. Journal of Internal Medicine 256:240-246.

Wirths O, Bethge T, Marcello A, Harmeier A, Jawhar S, Lucassen PJ, Multhaup G, Brody DL, Esparza T, Ingelsson M, Kalimo H, Lannfelt L, Bayer TA (2010) Pyroglutamate Abeta pathology in APP/PS1KI mice, sporadic and familial Alzheimer's disease cases. Journal of neural transmission 117:85-96.

Zanetti-Domingues LC, Tynan CJ, Rolfe DJ, Clarke DT, Martin-Fernandez M (2013) Hydrophobic fluorescent probes introduce artifacts into single molecule tracking experiments due to nonspecific binding. PloS one 8:e74200.

Zetterberg H, Blennow K (2013) Cerebrospinal fluid biomarkers for Alzheimer's disease: more to come? Journal of Alzheimer's disease : JAD 33 Suppl 1:S361-369.

Zhang WI (2011) Investigation of mRNA dynamics and protein synthesis upon neuronal activity. vol. Master Göttingen: University of Göttingen.

Zimmermann R, Lelental N, Ganslandt O, Maler JM, Kornhuber J, Lewczuk P (2011) Preanalytical sample handling and sample stability testing for the neurochemical dementia diagnostics. Journal of Alzheimer's disease : JAD 25:739-745. 